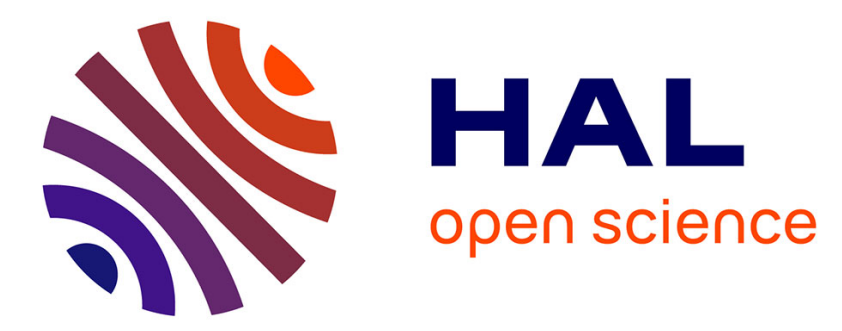

\title{
Optimal licensing of uncertain patents in the shadow of litigation
}

\author{
Rabah Amir, David Encaoua, Yassine Lefouili
}

\section{To cite this version:}

Rabah Amir, David Encaoua, Yassine Lefouili. Optimal licensing of uncertain patents in the shadow of litigation. Games and Economic Behavior, 2014, 88, pp.320-338. 10.1016/j.geb.2014.09.009 . hal01087234

\section{HAL Id: hal-01087234 \\ https://hal.science/hal-01087234}

Submitted on 25 Nov 2014

HAL is a multi-disciplinary open access archive for the deposit and dissemination of scientific research documents, whether they are published or not. The documents may come from teaching and research institutions in France or abroad, or from public or private research centers.
L'archive ouverte pluridisciplinaire HAL, est destinée au dépôt et à la diffusion de documents scientifiques de niveau recherche, publiés ou non, émanant des établissements d'enseignement et de recherche français ou étrangers, des laboratoires publics ou privés. 


\title{
Optimal Licensing of Uncertain Patents in the Shadow of Litigation*
}

\author{
Rabah Amir ${ }^{\dagger} \quad$ David Encaoua $a^{\ddagger} \quad$ Yassine Lefouili $^{\S}$
}

August 2014

\begin{abstract}
This paper investigates the choice of a licensing mechanism by the holder of a patent whose validity is uncertain. We provide sufficient conditions of a general nature under which the licensor prefers to use a per-unit royalty contract. In particular we show that this is the case for the holders of weak patents if the strategic effect of an increase in a potential licensee's unit cost on the equilibrium industry profit is positive. The latter condition is shown to hold in a Cournot (resp. Bertrand) oligopoly with homogeneous (resp. differentiated) products under general assumptions on the demands faced by firms. As a byproduct of our analysis, we contribute to the literature on the cost paradox in oligopoly by offering some new insights of independent interest regarding the effects of cost variations on Cournot and Bertrand equilibria.
\end{abstract}

Keywords: Licensing mechanisms, Uncertain patents, Patent litigation, Cost comparative statics. JEL Classification: D45, L10, O32, O34.

\footnotetext{
*A previous version of this paper was circulated under the title "Per-Unit Royalty vs Fixed Fee: The Case of Weak Patents." We are grateful to an associate editor and two anonymous referees for very useful comments and suggestions. We would also like to thank Claude d'Aspremont, Bertrand Gobillard, Christian Helmers, Patrick Rey, Isabel Ruhmer, Cédric Schneider, Yair Tauman, Jean Tirole, Yaron Yehezkel, and participants in various conferences and seminars for valuable comments and discussions.

${ }^{\dagger}$ University of Iowa. E-mail: rabah-amir@uiowa.edu

${ }^{\ddagger}$ Paris School of Economics, Université Paris-1 Panthéon Sorbonne. E-mail: encaoua@univ-paris1.fr

$\S$ Toulouse School of Economics. E-mail: yassine.lefouili@tse-fr.eu
} 


\section{Introduction}

Since the seminal contribution by Arrow (1962), analyzing the licensing contracts offered by patent holders has become an important topic in the economics of innovation and technology diffusion. Arrow compared the revenues that an outside innovator obtains from licensing a cost-reducing innovation to a competitive industry and to a monopolistic industry. He showed that when a per-unit royalty is charged, a perfectly competitive industry generates higher licensing revenues than a monopolistic one. Subsequently, Katz and Shapiro $(1985,1986)$ and Kamien and Tauman $(1984,1986)$ analyzed different licensing mechanisms (fixed fee, auction and per-unit royalty) when the potential licensees are members of an oligopoly. A key insight of the theoretical literature that has built on those seminal papers is that the optimal licensing mechanism depends on many factors, including the type of downstream competition, the degree of differentiation between products and whether the patent holder is active or not in the downstream market. These three factors have been shown to be critical in the sense that predictions regarding the optimal mechanism can be completely overturned by varying any of them. ${ }^{1}$

A common feature of the existing papers on the comparison of different licensing mechanisms is that patents are viewed as certain or "ironclad" rights, the validity of which is unquestionable. This clearly contradicts what we observe in practice: about half of the patents that are challenged before US courts are invalidated (Allison \& Lemley, 1998). ${ }^{2}$ It is now largely recognized that a patent is not a perfectly enforceable right, as are other forms of property. Patents correspond much more to uncertain or probabilistic rights because they only give a right to try to exclude by asserting the patent in court (Ayres and Klemperer, 1999; Shapiro, 2003; Lemley and Shapiro, 2005). Moreover, this uncertainty is strengthened by the fact that many applications are granted patent protection by the patent office (PO) even though they probably do not meet one or several of the statutory requirements: belonging to the patentable subject matters, utility, novelty and non-obviousness (or inventiveness). As a result, some of the uncertain patents are weak in the sense that they have a high probability of being invalidated by a court if challenged by a third party.

The proliferation of uncertain patents is due to several reasons. First, the major patent offices (USPTO, EPO and JPO) have insufficient resources to ensure an effective review process for the huge and growing number of patent applications (Friebel et al., 2006). Second, mistakes are unavoidable because the patentability requirements are difficult to assess, especially for newly patentable subject matters such as software, business methods and research tools. Third, the incentives provided to the

\footnotetext{
${ }^{1}$ For instance, it has been shown that under Cournot competition with homogeneous products, fixed fees dominate per-unit royalties when the licensor is an industry outsider (Kamien and Tauman, 1984, 1986; Kamien et al., 1992). However, the reverse result holds if the licensor is an industry insider (Shapiro, 1985; Wang, 1998; Kamien and Tauman, 2002; Sen, 2002; Sen and Tauman, 2007, 2012). Furthermore, under price competition with differentiated products, per-unit royalties dominate fixed fees when the products are close substitutes or, if not, when the size of the cost reduction is small, while the reverse holds if the products are weak substitutes and the innovation is large (Muto, 1993). The results are quite different if one considers the same differentiated product environment but assumes that firms compete in quantities instead of prices (Wang, 2002).

${ }^{2}$ This concerns the patent disputes that are not settled prior to the court judgement.
} 
examiners are inadequate for making them fully prosecute and reject applications that do not meet the standards (Farrell and Merges, 2004; Langinier and Marcoul, 2009; Lei and Wright, 2010).

This paper investigates the optimal licensing mechanism from the perspective of a licensor holding an uncertain patent and facing the threat of patent litigation. We consider a model in which a patent holder makes a license offer to potential licensees who can challenge the patent's validity if they do not accept the offer. The potential users of the patented technology are assumed to compete with each other in the output market but the type of competition between them is not specified. ${ }^{3}$

We focus throughout the paper on the case when the patent holder prefers to deter litigation rather than accomodate it. This scenario is supported by both theoretical arguments and empirical evidence that we discuss in detail in Section 3. Moreover, when the patent holder finds it optimal to accomodate litigation then it is maximizing its licensing revenues should the patent be ruled valid. Therefore, it is essentially acting as the holder of an ironclad patent. In that case, the problem of choosing a licensing mechanism for an uncertain patent is the same as its (extensively studied) counterpart for an ironclad patent.

In our baseline model the licensing contracts can involve the payment of either fixed fees or perunit royalties. We show that two opposite forces drive the patent holder's choice between these two instruments. On the one hand, the use of per-unit royalties allows the patent holder to increase the size of the aggregate profits (the sum of the licensor's and licensees' profits) by relaxing competition between the licensees. Per-unit royalties have this efficiency effect whenever a mild condition on the strategic effect of marginal costs on the licensees' profits is satisfied. On the other hand, fixed fee licensing results in a lower profit for a firm that challenges the patent but fails to invalidate it. This punishment effect makes the expected payoff of a challenger lower when fixed fees are used. Therefore, the rent that the patent holder has to leave to the licensees for litigation to be deterred is lower under a fixed fee contract than under a per-unit royalty contract.

When an unsuccessful challenger is driven out of the market under both types of contracts, there is no punishment effect. In that case, the patent holder chooses the mechanism that maximizes the aggregate profits, i.e. the per-unit royalty mechanism. However, when the punishment effect is at work, per-unit royalties will be preferred by the patent holder only if the magnitude of the latter is lower than that the magnitude of the efficiency effect. We show that this holds for sufficiently weak patents. The key reason for this is that the punishment effect is a second-order effect for weak patents while the efficiency effect is a first-order one. We also show that the superiority of per-unit royalty contracts for the licensing of weak patents remains true in three extensions of our baseline model that account for (i) litigation costs, (ii) the possibility of using two-part tariff contracts, and (iii) the possibility that the patent holder competes against the licensees in the output market.

Our paper contributes to three strands of literature:

1. The literature that compares various licensing mechanisms. ${ }^{4}$ Our contribution is to extend

\footnotetext{
${ }^{3}$ We assume only that a unique equilibrium in the competition game exists and set very mild assumptions on the resulting equilibrium profits (as functions of the unit costs).

${ }^{4}$ See Bhattacharya et al. (2012) for a recent survey on the licensing of ironclad patents and other R\&D arrangements.
} 
that comparison to patents whose validity is uncertain. This issue deserves scrutiny in light of the growing proliferation of uncertain patents and, in particular, weak ones. ${ }^{5}$ Our main result can be seen as a novel justification, based on the uncertainty over patent validity, for the use of per-unit royalties instead of fixed fees in licensing contracts. Explaining why patent holders prefer to use royalty contracts is important because, despite the frequent use of per-unit royalties in practice, ${ }^{6}$ a number of seminal theoretical models on licensing have concluded that the optimal licensing contract should involve the payment of a fixed fee (see e.g. Kamien, 1992). ${ }^{7}$ A key difference with the literature considering ironclad patents is that the superiority of per-unit royalties for the licensing of weak patents is a very robust result: It is independent of the type of downstream competition, the degree of product differentiation and whether the patent holder is active or not in the output market.

2. The literature on the licensing and litigation of uncertain patents (Aoki and $\mathrm{Hu}, 1999$; Farrell and Shapiro, 2008; Encaoua and Lefouili, 2009; Choi 2010). This literature has been mostly concerned with the inefficiencies stemming from the low private incentives to litigate a weak patent. The social harm of uncertain patents depends on how they are licensed out and, therefore, we argue that it is crucial to get a better understanding of the licensing mechanisms the holders of those patents use. ${ }^{8}$

3. The literature on the effects of cost variations on oligopolists' profits (Seade, 1985; Kimmel, 1992; Février and Linnemer, 2004). While the existing literature has focused on the (ambiguous) sign of the overall effect of cost variations on equilibrium profits, we investigate the sign of the strategic effect of a unilateral cost increase on industry profits. We show that this sign is unambiguously positive in the two most usual imperfect competition models under general (and commonly invoked) assumptions on the demand functions. An ancillary result is that we provide a lower bound on the overall effect of a unilateral cost increase on industry profits. ${ }^{9}$

The remainder of the paper is organized as follows. Section 2 presents the model. Section 3

\footnotetext{
${ }^{5}$ Bessen and Meurer (2008) argue that the inclusion of software and business methods in the patentable subject matters in the US has resulted in an increase in the share of weak patents among all the patents issued by the USPTO.

${ }^{6}$ See e.g. Taylor and Silberstone (1973) and Rostoker (1984). In particular, royalties are widely used for the licensing of standard-essential patents.

${ }^{7}$ Various other reasons have been put forward in the literature on ironclad patents to explain the use of royalties, including risk aversion (Bousquet et al., 1998), asymmetry of information (Gallini and Wright, 1990; Macho-Stadler and Pérez-Castrillo, 1991; Beggs, 1992; Sen 2005a), moral hazard (Macho-Stadler et al., 1996; Choi, 2001), product differentiation (Muto, 1993; Wang and Yang, 1999; Caballero-Sanz et al., 2002; Poddar and Sinha, 2004; Stamatopoulos and Tauman, 2007), strategic delegation (Saracho, 2002), integer nature of the number of licensees (Sen, 2005b), variation in the quality of innovation (Rockett, 1990).

${ }^{8}$ In Farrell and Shapiro (2008) and Encaoua and Lefouili (2009), the licensor is assumed to offer two-part tariff licensing contracts. However, in both papers a technical ad hoc assumption on the shape of the (endogenous) licensing revenue function is made to simplify the analysis by immediately guaranteeing that pure per-unit royalty contracts are optimal for the licensors of weak patents (in the class of contracts deterring litigation). In sharp contrast to the former papers, our result that the holder of a weak patent finds it optimal to use a per-unit royalty licensing contract is implied by a mild condition which has a natural economic interpretation and is shown to hold with broad generality in standard oligopoly models with general demand functions (as are all the assumptions made in our model).

${ }^{9}$ Besides the three strands of literature discussed above, this paper can also be related to the literature on pre-grant licensing (see e.g. Gans et al. 2008). The licensing of a technology covered by an uncertain patent and the licensing of a technology that is not patented yet have in common that they happen before some type of uncertainty is removed or reduced. However, they are different in that the public good nature of patent invalidation has strategic implications that are absent in the case of pre-grant licensing.
} 
characterizes the licensing contracts that deter litigation. In Section 4 we provide sufficient conditions under which the per-unit royalty mechanism is preferred by the patent holder. In Section 5, three extensions of our baseline model are considered. In Section 6, we show that the assumptions made on the equilibrium profits in our model and the (sufficient) conditions ensuring the superiority of the per-unit royalty mechanism in Section 4 are satisfied with broad generality for both a Cournot oligopoly with homogenous goods and a Bertrand oligopoly with differentiated goods. Section 7 concludes. All proofs are relegated to the Appendix.

\section{The model}

We consider an industry consisting of $n \geq 2$ symmetric risk-neutral firms producing at marginal cost $\bar{c}$ (fixed production costs are assumed to be zero). A firm $P$ outside the industry holds a patent covering a technology that, if used, allows a firm to reduce its unit cost from $\bar{c}$ to $\bar{c}-\epsilon$ where $\epsilon \in] 0, \bar{c}[$. We consider the following three-stage game: ${ }^{10}$

First stage: The patent holder $P$ offers all firms a licensing contract ${ }^{11}$ whereby a licensee can use the patented technology against payment of a per-unit royalty $r \in[0, \epsilon]^{12}$ or a fixed fee $F \geq 0 .{ }^{13}$

Second stage: The $n$ firms in the industry simultaneously and independently decide whether to purchase a license. If a firm does not accept the license offer, it can challenge the patent's validity before a court. ${ }^{14}$ The outcome of such a trial is uncertain: with probability $\theta>0$ the patent is upheld by the court and with probability $1-\theta$ it is invalidated. Hence, the parameter $\theta$ may be interpreted as the patent's quality or the patent's strength. If the patent is upheld, then a firm that does not purchase the license uses the old technology, thus producing at marginal cost $\bar{c}$ whereas a firm that accepted the license offer uses the new technology and pays the per-unit royalty $r$ or the fixed fee $F$ to the patent holder. ${ }^{15}$ If the patent is invalidated, all the firms, including those that accepted the

\footnotetext{
${ }^{10}$ This game is similar to the one in Encaoua and Lefouili (2009). However we set much weaker assumptions in the present paper and use this game to conduct a thorough analysis of the optimal licensing scheme from the patent holder's perspective.

${ }^{11}$ Following Farrell and Shapiro (2008) and Encaoua and Lefouili (2009), we focus on take-it-or-leave-it license offers.

${ }^{12}$ Farrell Shapiro (2008) recall that under patent law, a licensor can ask for royalties only for use of the patented technology. Under this rule the royalty $r$ cannot exceed the innovation size $\epsilon$. The reason is that a licensee would always prefer to use the "old" technology rather than pay $r>\epsilon$ for the use of the patented technology (see footnote 22 in Farrell and Shapiro, 2008). Moreover, setting a royalty higher than the innovation size can trigger an antitrust investigation. In particular, in Europe, the royalty imposed by the licensor has to be expressly linked to the patent and reflect its actual value, and the European Commission carefully considers if excessive royalties are being charged.

${ }^{13}$ Section 5.2 extends the analysis to two-part tariff contracts.

${ }^{14}$ For patents granted by the European Patent Office (EPO), the timing is slightly different. Indeed, any patent issued by the EPO can be opposed by a third party and the notice of opposition must be filed in writing at the EPO within nine months from the publication of the mention of the grant of the European patent.

${ }^{15}$ We assume that the patent holder commits not to license an unsuccessful challenger. Note however that our results will not be affected if post-litigation licensing occurs (because the patent holder cannot commit not to do that) as long as a patent upheld by the court is licensed in a way that does not leave any surplus to an unsuccessful challenger. This will always be the case under the fixed fee regime. It will also be the case under the per-unit royalty regime as long as the patent holder finds it optimal to license an unsuccessful challenger at the maximum per-unit royalty it accepts to pay, i.e. $r=\epsilon$. Under the specific setting of Cournot competition with homegeneous goods and linear demand, it can be checked that the latter holds if the innovation size $\epsilon$ is not too large.
} 
license offer can use for free the new technology and their common marginal cost is $\bar{c}-\epsilon$.

Third stage: The $n$ firms produce under the cost structure inherited from the second stage. We do not specify the type of competition that occurs. We only assume that there exists a unique equilibrium of the competition game for any cost structure and we set some general assumptions on the equilibrium profit functions. For this purpose, denote $\pi^{e}(k, c)$ (respectively $\left.\pi^{i}(k, c)\right)^{16}$ the equilibrium profit function, gross of any potential fixed cost (e.g. a fixed license fee) of a firm producing with marginal cost $c \leq \bar{c}$ (respectively with marginal cost $\bar{c}$ ) when $k \leq n$ firms produce at marginal cost $c$ and the remaining $n-k$ firms produce at the marginal cost $\bar{c}{ }^{17}$ We assume that the pre-licensing equilibrium profits of the $n$ firms is strictly positive, i.e. $\pi^{e}(n, \bar{c})>0$.

We now make the following general assumptions for any given $n$ and $k=1, \ldots, n$.

A1. The equilibrium profits of an efficient firm and an inefficient firm, i.e. $\pi^{e}(k, c)$ and $\pi^{i}(k, c)$ respectively, are both continuously differentiable in $c$ over the subset of $[0, \bar{c}]$ in which $\pi^{i}(k, c)>$ 0 . Furthermore, the equilibrium output $q^{e}(n, c)$ when all $n$ firms produce at marginal cost $c$ is continuously differentiable with respect to $c$ and strictly positive over $[0, \bar{c}]$.

A2. If the firms are symmetric (in terms of efficiency), an identical increase in all firms' marginal costs leads to a decrease in each firm's equilibrium profit: $\frac{\partial \pi^{e}}{\partial c}(n, c)<0$.

A3. An inefficient firm's equilibrium profit is increasing in the efficient firms' marginal cost: If $\pi^{i}(k, c)>0$ then $\frac{\partial \pi^{i}}{\partial c}(k, c)>0$ and if $\pi^{i}(k, c)=0$ then $\pi^{i}\left(k, c^{\prime}\right)=0$ for any $c^{\prime}<c$.

A4. A firm's profit is decreasing in the number of efficient firms in the industry: for any $c<\bar{c}$ and any $k<n$ it holds that $\pi^{e}(k, c)>\pi^{e}(k+1, c)$ and $\pi^{i}(k, c) \geq \pi^{i}(k+1, c)$.

A5. A firm's profit increases as it moves from the subgroup of inefficient firms to the subgroup of efficient firms: for any $c<\bar{c}$ and any $k<n$ it holds that $\pi^{i}(k, c)<\pi^{e}(k+1, c)$.

As we shall argue in precise detail in Section 6, all these assumptions are satisfied with broad generality in the two most widely used oligopoly models with general demand functions.

\section{Licenses deterring litigation}

If litigation occurs then, with probability $\theta$, the patent is upheld by the court (thus becoming an ironclad right) and, with probability $1-\theta$, it is invalidated and the technology can then be used for free by all firms. Thus, if the patent holder expects its license offer to trigger litigation, it should make an offer that maximizes the licensing revenues it will collect if the patent is ruled valid by the court. The patent holder would then essentially act as if the patent were ironclad. In other words, the uncertainty over the patent's validity does not affect the licensing terms in that scenario. We therefore consider in what follows only the class of license offers deterring litigation, for which the uncertainty over patent validity does matter. In doing so, we follow Farrell and Shapiro (2008)

\footnotetext{
${ }^{16}$ The superscript "e" (respectively "i") stands for "efficient" (respectively "inefficient").

${ }^{17}$ The fact that the profit function for a firm can be defined in terms of the number of firms that use the innovation, and not which firms use the innovation, relies on an implicit symmetry assumption. For instance, in the context of price competition with differentiated products, demands must be symmetric (i.e., products are symmetrically differentiated).
} 
who also focus on license offers such that litigation is avoided because they aim to investigate the social costs of the uncertainty over patent validity (which is resolved if litigation occurs). Farrell and Shapiro actually show that focusing on litigation-deterring contracts is much less restrictive than one might think: they show that the patent hoder finds it optimal to deter litigation (even in the absence of litigation costs) in (i) a symmetric Cournot oligopoly with linear inverse demand and costs as long as the number of licensees is three or more, and (ii) a symmetric Bertrand oligopoly with linear costs and a linear demand system (or, more generally, linear pass-through) as long as the number of licensees is two or more. This theoretical finding is supported by empirical evidence: the vast majority of patent disputes are settled using licensing agreements before a court decides whether the patent is valid or not (Allison and Lemley, 1998 and Lemley and Shapiro, 2005). Also, Zuniga and Guellec (2009) report that deterring litigation is one of the main motives put forward by firms when they are asked why they license out their patents.

We start our analysis by determining the license offers that deter litigation under each mechanism.

\subsection{Per-unit royalty mechanism}

Let us first examine a firm's incentives to challenge the patent's validity when the patent holder makes a license offer involving the payment of a per-unit royalty $r \in[0, \epsilon]$. A firm that decides not to purchase a license is always (weakly) better off challenging the patent's validity: if no other firm challenges the patent's validity it gets a payoff $\theta \pi^{i}(n-1, \bar{c}-\epsilon+r)+(1-\theta) \pi^{e}(n, \bar{c}-\epsilon)$ which is strictly greater than the profit $\pi^{i}(n-1, \bar{c}-\epsilon+r)$ it would get by not challenging the patent, and if some other firm challenges the patent's validity then it is indifferent between challenging and not. Thus, a situation where one or more firms do not buy a license and no firm challenges the patent's validity can never be an equilibrium of the second stage subgame. It follows that a license offer deters litigation if and only if it is accepted by all firms.

Assume that the patent holder makes a license offer (in the first stage) involving the payment of a per-unit royalty $r<\epsilon$. Let us show that in this case, any outcome with $k \leq n-2$ licensees cannot be an equilibrium. We have already shown that a situation where not all firms buy a license and no firm challenges the patent cannot be an equilibrium so we can focus on situations with $k \leq n-2$ licensees and at least one non-licensee challenging the patent. Any of the other $n-k-1 \geq 1$ nonlicensees has an incentive to unilaterally deviate by buying a license since it would get an expected profit of $\theta \pi^{e}(k+1, \bar{c}-\epsilon+r)+(1-\theta) \pi^{e}(n, \bar{c}-\epsilon)$ instead of the strictly lower expected profit $\theta \pi^{i}(k, \bar{c}-\epsilon+r)+(1-\theta) \pi^{e}(n, \bar{c}-\epsilon)$ if it remains a non-licensee. Therefore, any equilibrium of the second stage subgame involves at least $n-1$ firms if $r<\epsilon$. The latter result extends to the case $r=\epsilon$ if it is assumed, as will be the case from now on, that a firm which is indifferent between getting a license and not buying a license purchases one.

Let us now write the condition under which all firms accepting the license offer $r$ is an equilibrium of the second stage subgame. A firm anticipating that all other firms will purchase a license gets a profit equal to $\pi^{e}(n, \bar{c}-\epsilon+r)$ if it accepts the license offer. If it does not and challenges the patent's 
validity then with probability $\theta$, the patent is upheld by the court and the challenger gets a profit equal to $\pi^{i}(n-1, \bar{c}-\epsilon+r)$ and, with probability $1-\theta$, the challenger gets a profit of $\pi^{e}(n, \bar{c}-\epsilon)$ (and so do all other firms). Thus, a firm challenging the patent's validity when all other firms accept the license offer, gets an expected profit of $\theta \pi^{i}(n-1, \bar{c}-\epsilon+r)+(1-\theta) \pi^{e}(n, \bar{c}-\epsilon)$. Therefore, all firms accepting the license offer is an equilibrium if and only if:

$$
\pi^{e}(n, \bar{c}-\epsilon+r) \geq \theta \pi^{i}(n-1, \bar{c}-\epsilon+r)+(1-\theta) \pi^{e}(n, \bar{c}-\epsilon) .
$$

The next lemma characterizes the values of the per-unit royalty set by the licensor that induce all firms to buy a license (thus deterring litigation).

Lemma 1 Define $\tilde{r}(\theta)$ as the unique solution in $r$ to the following equation:

$$
\pi^{e}(n, \bar{c}-\epsilon+r)=\theta \pi^{i}(n-1, \bar{c}-\epsilon+r)+(1-\theta) \pi^{e}(n, \bar{c}-\epsilon) .
$$

Then all firms accepting to pay a per-unit royalty $r$ is an equilibrium if and and only if $r \leq \tilde{r}(\theta)$.

\subsection{Fixed fee mechanism}

The previous observation that a license offer deters litigation if and only if it is accepted by all firms

remains true when the licensor uses a fixed fee scheme. For a license offer involving the payment of a fixed fee $F$ to be accepted by all firms, the following condition must hold:

$$
\pi^{e}(n, \bar{c}-\epsilon)-F \geq \theta \pi^{i}(n-1, \bar{c}-\epsilon)+(1-\theta) \pi^{e}(n, \bar{c}-\epsilon)
$$

which can be rewritten as:

$$
F \leq \theta\left[\pi^{e}(n, \bar{c}-\epsilon)-\pi^{i}(n-1, \bar{c}-\epsilon)\right]
$$

The next lemma is the counterpart of Lemma 1 for the fixed fee mechanism.

Lemma 2 All firms accepting to pay the fixed fee $F$ to use the patented technology is an equilibrium if and only if $F \leq \tilde{F}(\theta) \equiv \theta\left[\pi^{e}(n, \bar{c}-\epsilon)-\pi^{i}(n-1, \bar{c}-\epsilon)\right]$.

\section{Optimal licensing mechanism}

The optimal per-unit royalty contract deterring litigation solves the following maximization program:

$$
\begin{gathered}
\max _{r \geq 0} n r q^{e}(n, \bar{c}-\epsilon) \\
\text { s.t. } r \leq \tilde{r}(\theta)
\end{gathered}
$$


while the optimal fixed fee contract deterring litigation is given by

$$
\begin{aligned}
& \quad \max _{F \geq 0} n F \\
& \text { s.t. } F \leq \tilde{F}(\theta)
\end{aligned}
$$

It is obvious that the constraint of the latter maximization program is binding at the optimum. For the sake of exposition we will also also assume that the constraint of the program defining the optimal per-unit royalty contract is binding at the optimum. ${ }^{18}$ Note however that relaxing this assumption can only strengthen the subsequent results about the superiority of the per-unit royalty mechanism.

\subsection{Efficiency effect versus punishment effect}

Denoting $\tilde{P}_{r}(\theta)$ (resp. $\tilde{P}_{F}(\theta)$ ) the licensing revenues generated by the optimal per-unit royalty (resp. fixed fee) contract deterring litigation, we have

$$
\tilde{P}_{r}(\theta)=n \tilde{r}(\theta) q^{e}(n, \bar{c}-\epsilon+\tilde{r}(\theta))
$$

and

$$
\tilde{P}_{F}(\theta)=n \tilde{F}(\theta)=n \theta\left[\pi^{e}(n, \bar{c}-\epsilon)-\pi^{i}(n-1, \bar{c}-\epsilon)\right]
$$

This, combined with $\pi^{e}(n, \bar{c}-\epsilon+\tilde{r}(\theta))=\theta \pi^{i}(n-1, \bar{c}-\epsilon+\tilde{r}(\theta))+(1-\theta) \pi^{e}(n, \bar{c}-\epsilon)$, yields

$$
\tilde{P}_{r}(\theta)-\tilde{P}_{F}(\theta)=A(\theta)+B(\theta) .
$$

where

$$
A(\theta) \equiv n\left[\pi^{e}(n, \bar{c}-\epsilon+\tilde{r}(\theta))+\tilde{r}(\theta) q^{e}(n, \bar{c}-\epsilon+\tilde{r}(\theta))-\pi^{e}(n, \bar{c}-\epsilon)\right]
$$

and

$$
B(\theta) \equiv-n \theta\left[\pi^{i}(n-1, \bar{c}-\epsilon+\tilde{r}(\theta))-\pi^{i}(n-1, \bar{c}-\epsilon)\right]
$$

The term $A(\theta)$ captures an efficiency effect : it is the difference between the aggregate profits generated under the optimal per-unit royalty contract and those under the optimal fixed fee contract. This term is always positive if the following condition holds:

$$
\pi^{e}\left(n, c^{\prime}\right)-\pi^{e}(n, c)>-\left(c^{\prime}-c\right) q^{e}\left(n, c^{\prime}\right) \text { for any } c, c^{\prime} \in[\bar{c}-\epsilon, \bar{c}] \text { such that } c<c^{\prime}
$$

The decomposition

$$
\pi^{e}\left(n, c^{\prime}\right)-\pi^{e}(n, c)=-\left(c^{\prime}-c\right) q^{e}\left(n, c^{\prime}\right)+\left(p^{e}\left(n, c^{\prime}\right)-c\right) q^{e}\left(n, c^{\prime}\right)-\left(p^{e}(n, c)-c\right) q^{e}(n, c)
$$

\footnotetext{
${ }^{18}$ It can be easily shown that this will always be the case for $\theta$ sufficiently small.
} 
shows that the overall effect of an increase in marginal costs on equilibrium profits can be split into a cost effect, captured by the term $-\left(c^{\prime}-c\right) q^{e}\left(n, c^{\prime}\right)$, and a strategic effect, captured by the term $\left(p^{e}\left(n, c^{\prime}\right)-c\right) q^{e}\left(n, c^{\prime}\right)-\left(p^{e}(n, c)-c\right) q^{e}(n, c)$. The cost effect is obviously negative. Condition (3) means that the strategic effect of a marginal cost increase on equilibrium profits is positive.

Let us now explain why Condition (3) is sufficient to ensure that the per-unit royalty mechanism generates higher aggregate profits than the fixed fee mechanism. Per-unit royalties do not affect the marginal cost of production from an aggregate perspective: the additional marginal cost incurred by the licensees is fully captured by the licensor. However, they distort the firms' price/output decisions since the effective marginal cost of the licensees increases. The effect of this distorsion on the aggregate profits is the same as the (previously defined) strategic effect of a marginal cost increase on the licensees' profits. Therefore whenever the latter is positive, per-unit royalties increase aggregate profits with respect to fixed fees.

To the best of our knowledge, Condition (3) has not been studied in the literature on the effects of cost variations on oligopolists' profits which has mainly focused on the overall effect of cost changes on profits (e.g. Seade, 1985, Kimmel, 1992; Février and Linnemer 2004). In Section 6, we will establish that this condition is satisfied with broad generality in the widely used settings of Cournot competition with homogeneous products and Bertrand competition with differentiated products.

Let us now turn to $B(\theta)$. Since a challenger gets the same profit under both mechanisms if the patent is invalidated, $B(\theta)$ is the difference between the expected profits a challenger would get under the optimal per-unit royalty contract deterring litigation and its fixed fee counterpart. It captures a punishment effect: an unsuccessful challenger gets a (weakly) lower profit under the fixed fee mechanism than under the per-unit royalty mechanism because its licensed competitors are more efficient under the former. Therefore, the rent that the patent holder needs to leave to each licensee in order to deter litigation is (weakly) lower under the fixed fee mechanism.

We can therefore conclude that, under Condition (3), the choice of a licensing mechanism is driven by two conflicting considerations. On the one hand, the efficiency effect gives the patent holder an incentive to use the mechanism that maximizes aggregate profits, i.e. the per-unit royalty mechanism. On the other hand, the punishment effect provides an incentive to choose the mechanism that leaves a rent as low as possible to the licensees, i.e. the fixed fee mechanism.

While the efficiency effect is always strictly positive (under Condition (3)), the punishment effect is only weakly negative. We will therefore distinguish between the case when it is absent $(B(\theta)=0)$ and the case when it is at work $(B(\theta)<0)$.

\subsection{Optimal mechanism when there is no punishment effect}

Assume here that $B(\theta)=0$. Note first that this holds if and only if $\pi^{i}(n-1, \bar{c}-\epsilon+\tilde{r}(\theta))=0$ (by A3). In words, a necessary and sufficient condition for the punishment effect to be zero is that an unsuccessful challenger gets the harshest possible punishment under the optimal per-unit royalty contract (and a fortiori under its fixed fee counterpart): it gets driven out of the market. In that 
case, the marginal cost of the licensees is irrelevant for an unsuccessful challenger. This scenario is more likely to hold the more competitive the industry.

The next proposition follows from the analysis in Section 4.1.

Proposition 1 Assume that an unsuccessful challenger is driven out of the market under both mechanisms (i.e. $\pi^{i}(n-1, \bar{c}-\epsilon+\tilde{r}(\theta))=0$ ). Then the optimal per-unit royalty contract deterring litigation generates higher licensing revenues than its fixed fee counterpart if Condition (3) holds.

A simple intuition for this proposition can be provided through an alternative interpretation of Condition (3): the latter formalizes, in our general competitive setting, the intuitive idea that an increase in marginal cost relaxes competition. To see why notice first that Condition (3) also means that an "artificial" increase in all firms' marginal costs has a positive effect on the equilibrium profits in a symmetric industry. The term "artificial" refers to a situation in which firms manage to commit to the prices/outputs corresponding to a higher marginal cost while their effective marginal cost remains unchanged. Moreover, we will show in Section 6 that, in the specific context of a symmetric Cournot oligopoly with homogenenous products (resp. Bertrand oligopoly with differentiated products), a key condition for Condition (3) to hold is that the equilibrium output (resp. price) is decreasing (resp. increasing) in the marginal cost of production.

With this interpretation in mind, it becomes clear that per-unit royalties allow the patent holder to relax competition between the licensees, which results in higher aggregate profits. In the absence of the punishment effect, the choice of a licensing mechanism is fully driven by the efficiency effect and, therefore, the patent holder chooses to use a per-unit royalty contract.

\subsection{Optimal mechanism when the punishment effect is at work}

Assume now that $B(\theta)<0$. Then the condition that the efficiency effect is positive $(A(\theta)>0)$ is no longer sufficient for the per-unit royalty mechanism to dominate the fixed fee mechanism. Since the punishment effect is negative, a per-unit royalty contract will be used only if the magnitude of the efficiency effect is higher than that of the punishment effect (i.e. $A(\theta)>|B(\theta)|$ ). While this may not be the case on the whole parameter space in our general setting, it turns out that it is always true for sufficiently weak patents. The reason is that the effect of leaving more profits to the licensees under the per-unit royalty mechanism on the patent holder's profit, which is captured by $B(\theta)$, is at most, a second-order term for $\theta$ sufficiently small (because $B(0)=0$ and $\left.B^{\prime}(0)=0\right)$. In contrast, the efficiency effect $A(\theta)$ is a first-order term (because $A(0)=0$ and $A^{\prime}(0)>0$ under Condition (3)).

The next result provides a condition, which is less restrictive than Condition (3), that ensures the superiority of the per-unit royalty mechanism for the licensing of (sufficiently) weak patents.

Proposition 2 For a sufficiently weak patent, the optimal per-unit royalty contract deterring litigation provides higher licensing revenues than the optimal fixed fee contract deterring litigation if

$$
\frac{\partial \pi^{e}}{\partial c}(n, \bar{c}-\epsilon)>-q^{e}(n, \bar{c}-\epsilon)
$$


Condition (4) is a local version of Condition (3) and, therefore, has the same economic interpretation. Section 6 will show the mildness of Condition (4) but, because Proposition 2 provides a local result, it is not informative regarding the range of patent strength values $\theta$ for which the per-unit royalty mechanism is preferred by the licensor when an unsuccessful challenger remains active in the market. The following example shows that this range can be substantially wide.

Example Consider the special case of Cournot competition with linear demand $p=a-Q$ and assume that $\epsilon \leq \frac{a-\bar{c}}{2(n-1)}$. In that environment $\pi^{i}(n-1, \bar{c}-\epsilon)>0$, i.e. a challenger would always remain active in the market should the patent be upheld. Long but straightforward computations show that a threshold $\hat{\theta}$ exists such that the optimal per-unit royalty contract deterring litigation generates higher licensing revenues than its fixed fee counterpart if $\theta$ is greater than $\hat{\theta}$. In this setting, the parameters $a, \bar{c}$ and $\epsilon$ affect the comparison of $\tilde{P}_{r}(\theta)$ and $\tilde{P}_{F}(\theta)$ only through the ratio $\frac{a-\bar{c}}{\epsilon}$. We compute $\hat{\theta}$ for the set of the 1000 pairs $\left(n, \frac{a-\bar{c}}{\epsilon}\right)$ such that $n=2,3, \ldots, 11$ and $\frac{a-\bar{c}}{\epsilon}=2(n-1)+i$ where $i=1,2, \ldots, 100$ and find values that are all greater than 0.5 . More specifically all values are within the interval $[0.501,0.678]$. This shows that, even when the punishment effect is at work, the superiority of the per-unit royalty scheme is not associated only with small values of $\theta$.

\section{Extensions}

We now assess the robustness of Proposition 2 by considering three extensions of our baseline model.

\subsection{Litigation costs}

Let us assume in this section that a firm that challenges the patent's validity before a court has to incur some legal costs $C \geq 0 .{ }^{19}$ It is straightforward that the higher those costs the higher the licensing revenues the patent holder can extract from the licensees without triggering litigation. This qualitative observation holds for both mechanisms. However, we show in what follows that, on the quantitative side, the marginal effect of litigation costs on the patent holder's licensing revenues is higher under the per-unit royalty mechanism than under the fixed fee mechanism if condition (4) holds. This implies that the result in Proposition 2 remains true - and is actually strenghtened - if the model is extended to include (small) legal costs that any challenger must incur.

Suppose first that the patent holder makes a license offer involving the payment of a per-unit royalty $r \in[0, \epsilon[$. Note that the inclusion of legal costs in our setting does not affect the fact that the strategy "not buy a license and not challenge the patent's validity" is always dominated by the strategy "buy a license". Therefore, the only way a patent holder can deter litigation is to make a

\footnotetext{
${ }^{19}$ Assuming that the patent holder incurs positive legal costs as well does not alter the subsequent analysis. The reason is that we focus on the scenario in which the patent holder finds its optimal to deter litigation. Note that including positive litigation costs for the patent holder actually make this scenario more likely.
} 
license offer that is accepted by all firms. This will be the case if and only if

$$
\pi^{e}(n, \bar{c}-\epsilon+r) \geq \theta \pi^{i}(n-1, \bar{c}-\epsilon+r)+(1-\theta) \pi^{e}(n, \bar{c}-\epsilon)-C .
$$

It is easily shown the latter constraint is met if and only if $r \leq \tilde{r}(\theta, C)$ where $\tilde{r}(\theta, C)$ is the solution in $r$ to the equation

$$
\pi^{e}(n, \bar{c}-\epsilon+r)=\theta \pi^{i}(n-1, \bar{c}-\epsilon+r)+(1-\theta) \pi^{e}(n, \bar{c}-\epsilon)-C
$$

and that, for $\theta$ and $C$ sufficiently small, the optimal per-unit royalty license deterring litigation involves the payment of the royalty $\tilde{r}(\theta, C)$ (i.e. the constraint is binding). Note also that $\tilde{r}(\theta, C)$ is strictly increasing in both its arguments.

Suppose now that the patent holder makes a license offer involving the payment of a fixed fee $F \geq 0$. Such a license offer is accepted by all firms if and only if

$$
\pi^{e}(n, \bar{c}-\epsilon)-F \geq \theta \pi^{i}(n-1, \bar{c}-\epsilon)+(1-\theta) \pi^{e}(n, \bar{c}-\epsilon)-C
$$

and, therefore, the optimal fixed fee license deterring litigation involves the payment of the fee

$$
\tilde{F}(\theta, C)=\theta\left[\pi^{e}(n, \bar{c}-\epsilon)-\pi^{i}(n-1, \bar{c}-\epsilon)\right]+C .
$$

Let us now compare the licensing revenues derived by the patent holder under the two mechanisms. Under the optimal per-unit royalty contract, they are given by

$$
\tilde{P}_{r}(\theta, C)=n \tilde{r}(\theta, C) q^{e}(n, \bar{c}-\epsilon+\tilde{r}(\theta, C))
$$

and under the optimal fixed fee contract, they are given by

$$
\tilde{P}_{F}(\theta, C)=n \tilde{F}(\theta, C)=n \theta\left[\pi^{e}(n, \bar{c}-\epsilon)-\pi^{i}(n-1, \bar{c}-\epsilon)\right]+n C .
$$

Since $\tilde{P}_{r}(0,0)=\tilde{P}_{F}(0,0)$, a sufficient condition for the existence of $\tilde{\theta}>0$ and $\tilde{C}>0$ such that the inequality $\tilde{P}_{r}(\theta, C)>\tilde{P}_{F}(\theta, C)$ holds for any $\theta<\tilde{\theta}$ and $C<\tilde{C}$ is that

$$
\frac{\partial \tilde{P}_{r}}{\partial \theta}(0,0)>\frac{\partial \tilde{P}_{F}}{\partial \theta}(0,0)
$$

and

$$
\frac{\partial \tilde{P}_{r}}{\partial C}(0,0)>\frac{\partial \tilde{P}_{F}}{\partial C}(0,0)
$$

The former inequality has already been shown to be equivalent to Condition (4). Surprisingly enough, 
the latter inequality is equivalent to Condition (4) too. Indeed,

$$
\frac{\partial \tilde{P}_{F}}{\partial C}(0,0)=n
$$

and

$$
\frac{\partial \tilde{P}_{r}}{\partial C}(0,0)=n \frac{\partial r}{\partial C}(0,0) q^{e}(n, \bar{c}-\epsilon)
$$

Differentiating with respect to $C$ the equation defining $\tilde{r}(\theta, C)$ at point $(\theta, C)=(0,0)$, we get: $\frac{\partial r}{\partial C}(0,0)=-\frac{1}{\frac{\partial \pi^{e}}{\partial c}(n, \bar{c}-\epsilon)}$. Thus,

$$
\frac{\partial \tilde{P}_{r}}{\partial C}(0,0)=-\frac{n q^{e}(n, \bar{c}-\epsilon)}{\frac{\partial \pi^{e}}{\partial c}(n, \bar{c}-\epsilon)} .
$$

Hence

$$
\frac{\partial \tilde{P}_{r}}{\partial C}(0,0)>\frac{\partial \tilde{P}_{F}}{\partial C}(0,0) \Longleftrightarrow \frac{\partial \pi^{e}}{\partial c}(n, \bar{c}-\epsilon)>-q^{e}(n, \bar{c}-\epsilon) .
$$

Therefore, the result in Proposition 2 is robust - and is actually strengthened ${ }^{20}$ - in the presence of relatively small legal costs.

\subsection{Two-part tariff contracts}

Assume in this section that the patent holder can offer a two-part tariff licensing contract involving the payment of a fixed fee $F \geq 0$ and a per-unit royalty $r \geq 0$. The optimal two-part tariff contract $(\hat{F}(\theta), \hat{r}(\theta))$ deterring litigation is a solution to the following maximization program

$$
\begin{gathered}
\max _{F \geq 0, r \in[0, \epsilon]} n\left(F+r q^{e}(n, \bar{c}-\epsilon+r)\right) \\
\text { s.t. } \pi^{e}(n, \bar{c}-\epsilon+r)-F \geq \theta \pi^{i}(n-1, \bar{c}-\epsilon+r)+(1-\theta) \pi^{e}(n, \bar{c}-\epsilon) .
\end{gathered}
$$

Since the objective function is increasing in $F$, the constraint has to be binding at the optimum. Therefore, the optimal two-part tariff contract $(\hat{F}(\theta), \hat{r}(\theta))$ is such that $\hat{F}(\theta)=\pi^{e}(n, \bar{c}-\epsilon+\hat{r}(\theta))-$ $\theta \pi^{i}(n-1, \bar{c}-\epsilon+\hat{r}(\theta))-(1-\theta) \pi^{e}(n, \bar{c}-\epsilon)$ and $\hat{r}(\theta)$ is a solution to

$$
\begin{gathered}
\max _{r \in[0, \epsilon]}\left[r q^{e}(n, \bar{c}-\epsilon+r)+\pi^{e}(n, \bar{c}-\epsilon+r)-\theta \pi^{i}(n-1, \bar{c}-\epsilon+r)-(1-\theta) \pi^{e}(n, \bar{c}-\epsilon)\right] \\
\text { s.t. } \pi^{e}(n, \bar{c}-\epsilon+r) \geq \theta \pi^{i}(n-1, \bar{c}-\epsilon+r)+(1-\theta) \pi^{e}(n, \bar{c}-\epsilon) .
\end{gathered}
$$

Note that the latter constraint could be rewritten as $r \leq \tilde{r}(\theta)$, and that $\hat{F}(\theta)=0$ if and only if $\hat{r}(\theta)=\tilde{r}(\theta)$, i.e. the constraint is binding. The next proposition shows that our finding that

\footnotetext{
${ }^{20}$ The free riding problem arising from the public good nature of patent invalidation is amplified when a potential challenger needs to incur positive litigation costs. The fact that $\frac{\partial \tilde{P}_{r}}{\partial C}(0,0)>\frac{\partial \tilde{P}_{F}}{\partial C}(0,0)$ under Condition (4) implies that, under the latter, the per-unit royalty mechanism allows the patent holder to exploit the amplification of the free riding problem better than the fixed-fee mechanism (for weak patents and small litigation costs).
} 
the holder of a sufficiently weak patent finds it optimal to use a per-unit royalty contract whenever Condition (4) holds, extends to a setting where the larger set of two-part tariff contracts is considered.

Proposition 3 For sufficiently weak patents, the optimal two-part tariff licensing contract deterring litigation is a pure per-unit royalty contract if:

$$
\frac{\partial \pi^{e}}{\partial c}(n, \bar{c}-\epsilon)>-q^{e}(n, \bar{c}-\epsilon)
$$

\subsection{Internal patent holder}

Let us consider the case where the patent holder is active in the output (downstream) market. More specifically, we assume that one of the $n$ firms operating in the market, say firm 1 , gets a patent on a technology that lowers the unit production cost from $\bar{c}$ to $\bar{c}-\epsilon$. We assume that $n \geq 3$ (as we want to have at least two potential licensees).

Here again, we assume that there exists a unique equilibrium to the competition game for any cost structure (with identical market profits for firms producing at the same unit cost) and we set some general assumptions on the equilibrium profit functions. We focus on industry cost structures that can emerge following the licensing game, that is, situations in which: one firm - the patent holder - produces at unit cost $\bar{c}-\epsilon$, a number $k \leq n-1$ of firms - the licensees - produce at a unit cost $c \in[\bar{c}-\epsilon, \bar{c}]$ and the remaining $n-k$ firms - the non-licensees - produce at unit cost $\bar{c}$. We denote by $\pi^{p}(k, c), \pi^{l}(k, c)$ and $\pi^{n}(k, c)$ the equilibrium market profits of the patent holder, a licensee producing at an effective unit cost $c$ and a non-licensee respectively.

Given the new environment we consider, we need to replace the assumptions A1-A5 made in our baseline model with the following alternative, but related, assumptions:

A1'. The equilibrium profits $\pi^{p}(k, c), \pi^{l}(k, c)$ and $\pi^{n}(k, c)$ are continuously differentiable in $c$ over $[0, \bar{c}]$ over the subset of $[0, \bar{c}]$ in which $\pi^{n}(c, k)>0$. Furthermore, the function $c \rightarrow q^{l}(n, c)$ is continuously differentiable over the subset of $[0, \bar{c}]$ in which it is strictly positive.

A2'. An identical increase in the costs of all firms but the patent holder decreases each one of those firms' equilibrium profit: $\frac{\partial \pi^{l}}{\partial c}(n-1, c)<0$.

A3'. A non-licensee's equilibrium profit is increasing in the licensees' unit cost: If $\pi^{n}(k, c)>0$ then $\frac{\partial \pi^{n}}{\partial c}(k, c)>0$ and if $\pi^{n}(k, c)=0$ then $\pi^{n}\left(k, c^{\prime}\right)=0$ for any $c^{\prime}<c$.

A4'. A firm's market profit is decreasing in the number of licensees in the industry: for any $c<\bar{c}$ and any $k<n-1$ it holds that $\pi^{p}(k, c)>\pi^{p}(k+1, c) ; \pi^{l}(k, c)>\pi^{l}(k+1, c)$ and $\pi^{n}(k, c) \geq \pi^{n}(k+1, c)$. A5'. A firm's market profit increases as it moves from the subgroup of non-licensees to the subgroup of licensees: for any $c<\bar{c}$ and any $k<n-1$ it holds that $\pi^{n}(k, c)<\pi^{l}(k+1, c)$.

The comparison of the innovator's overall profit, i.e. the sum of its market profit and licensing revenues, under the two licensing mechanisms, yields the following result:

Proposition 4 For sufficiently weak patents, the optimal per-unit royalty contract deterring litiga- 
tion generates higher overall profit for the patent holder than its fixed fee counterpart if

$$
\frac{\partial \pi^{p}}{\partial c}(n-1, \bar{c}-\epsilon)+(n-1) \frac{\partial \pi^{l}}{\partial c}(n-1, \bar{c}-\epsilon)>-(n-1) q^{l}(n, \bar{c}-\epsilon) .
$$

Moreover, the reverse holds if the reverse strict inequality is satisfied.

To see how Condition (5) compares to its counterpart when the patent holder is not active on the market, i.e. Condition (4), let us rewrite both of them with the same notations. For that purpose, let us denote by $\Pi^{*}\left(c_{1}, c_{2}, \ldots, c_{n}\right)$ the sum of all firms' equilibrium market profits, i.e. the equilibrium (downstream) industry profit, and $q_{i}^{*}\left(c_{1}, c_{2}, \ldots, c_{n}\right)$ firm i's output when each firm $j=1,2, \ldots, n$ produces at unit cost $c_{j}$. The sufficient condition for a patent holder who is an industry outsider to prefer the per-unit royalty mechanism for sufficiently weak patents can be rewritten as (replacing $\bar{c}-\epsilon$ with the generic variable $c$ ):

$$
\sum_{i=1}^{n} \frac{\partial \Pi^{*}}{\partial c_{i}}(c, c, \ldots, c)>-\sum_{i=1}^{n} q_{i}^{*}(c, c, \ldots, c) .
$$

The sufficient condition for a patent holder who is an industry insider to prefer the per-unit royalty mechanism for sufficiently weak patents can be rewritten as (replacing again $\bar{c}-\epsilon$ by the generic variable $c$, and denoting $P$ the patent holder):

$$
\sum_{\substack{i=1 \\ i \neq P}}^{n} \frac{\partial \Pi^{*}}{\partial c_{i}}(c, c, \ldots, c)>-\sum_{\substack{i=1 \\ i \neq P}}^{n} q_{i}^{*}(c, c, \ldots, c) .
$$

The two inequalities have very close interpertations: Condition (6) means that the strategic effect of an identical increase in all firms' (common) unit cost on the industry profit is positive and Condition (7) means that the strategic effect of an increase in the costs of all firms but one on the industry profits is positive (firms being equally efficient initially). Note also that both conditions are implied by the following inequality when it holds for any $i=1,2, \ldots, n$ :

$$
\frac{\partial \Pi^{*}}{\partial c_{i}}(c, c, \ldots, c)>-q_{i}^{*}(c, c, \ldots, c) \text {. }
$$

This condition means that when firms are equally efficient initially, the strategic effect of an increase in one firm's unit cost on the industry profit ${ }^{21}$ is positive.

We next show that Condition (8) holds (i) for standard Cournot competition under complete generality, and (ii) for Bertrand competition with differentiated products under strategic complementarity, provided existence an uniqueness of a pure-strategy equilibrium hold in these two environments. It then follows that both Conditions (6) and (7) hold since they are implied by Condition (8).

\footnotetext{
${ }^{21}$ What we call "industry profit" is the sum of all market profits.
} 


\section{Two standard oligopoly applications}

In this section, we provide sufficient conditions of a general nature on the primitives of the two most widely used models of imperfect competition, which lead to Assumptions A1-A5 and A1'-A5' and Conditions (3), (4) and (5) being verified. Since some of the results below are new to the oligopoly literature, and of some independent interest, we derive them for fully asymmetric versions of the Cournot and Bertrand oligopolies with linear costs. Accordingly, we also change the notation as needed, relative to the other parts of the paper.

\subsection{Cournot competition with homogeneous products}

Consider an industry consisting of $n$ firms competing in Cournot fashion. Firm $i$ 's marginal cost is denoted $c_{i}$ (fixed production costs are assumed to be zero or otherwise sunk). Suppose the firms face an inverse demand function $P(\cdot)$ satisfying the following minimal conditions:

C1 $P(\cdot)$ is twice continuously differentiable and $P^{\prime}(\cdot)<0$ whenever $P(\cdot)>0$.

C2 $P(0)>c_{i}>P(Q)$ for $Q$ sufficiently high, $i=1,2, \ldots, n$.

C3 $P^{\prime}(Q)+Q P^{\prime \prime}(Q)<0$ for all $Q \geq 0$ with $P(\cdot)>0$.

These assumptions are quite standard. C3 is the familiar condition used by Novshek (1985) to ensure downward-sloping reaction curves (for any cost function). It states that each firm's marginal revenue is decreasing in rivals' output (see Amir, 1996 for an alternative condition).

Firm $i$ 's profit function and reaction correspondence are (here, $Q_{-i}=\sum_{j \neq i} q_{j}$ )

$$
\pi_{i}\left(q_{i}, Q_{-i}\right)=q_{i}\left[P\left(q_{i}+Q_{-i}\right)-c_{i}\right] \text { and } r_{i}\left(Q_{-i}\right)=\arg \max _{q_{i} \geq 0} \pi_{i}\left(q_{i}, Q_{-i}\right)
$$

The next proposition provides general conditions under which Assumptions A1-A5 and A1'-A5' hold for a Cournot oligopoly.

Proposition 5 Under Assumptions C1-C3,

(a) There exists a unique Cournot equilibrium.

(b) Firm $i$ 's equilibrium output $q_{i}^{*}$ and profit $\pi_{i}^{*}$ are differentiable in $c_{i}$ and in $c_{j}$ for any $j \neq i$.

(c) Firm i's equilibrium profit $\pi_{i}^{*}$ is decreasing in $c_{i}$ and increasing in $c_{j}$ for any $j \neq i$.

If in addition, the game is symmetric (with $c$ denoting the unit cost), then

(d) The unique Cournot equilibrium is symmetric.

(e) The equilibrium output $q^{*}$ strictly decreases in $c$.

(f) Per-firm equilibrium profit $\pi^{*}$ decreases in $c$.

It is straightforward to relate the different parts of Proposition 5 to Assumptions A1-A5 and A1'-A5'. Part (a) is needed to avoid vacuous statements. Assumptions A1 and A1' are implied by part (b) and the proof of part (e). Assumption A2 follows from part (f) and Assumption A2' 
follows from combining part (f) with part (c). Assumptions A3 and A3' are implied by part (c). Assumptions A4 and A4' follow from repeated applications of part (c), with one rival firm's cost decreasing at a time. Assumptions A5 and A5' follow from part (c).

We now discuss the scope of these assumptions, focusing on parts (f) and (c), the other assumptions being well known for existence and uniqueness of Cournot equilibrium. Though intuitive, part (f) actually has a less universal scope than one might think. Indeed, there is an extensive literature dealing with taxation in oligopolistic industries and one of its key insights is that a common cost increase can lead to some firms benefiting at the expense of others (Seade, 1985, Kimmel, 1992, and Février and Linnemer, 2004). More surprisingly, in a symmetric setting, a cost increase may be beneficial to all firms, when the inverse demand function is sufficiently convex. In light of this result, known as the cost paradox, part (f) may be viewed as giving sufficient conditions for this counter-intuitive effect of taxation not to arise.

Since the cost paradox literature considers cost increases that are common to all firms, it does not deal with the profit effects of a unilateral cost change, as in the two novel results of part (c). In light of this discussion, it emerges that ruling out the cost paradox and its plausible implications is one of the most restrictive assumptions of the present setting. Assumption C3 is then appropriate since it guarantees existence and uniqueness of Cournot equilibrium and the absence of the cost paradox.

Proposition 6 Under Assumptions C1-C3,

(i) Condition (8) and, therefore, Conditions (4) and (5) are verified.

(ii) Condition (3) holds whenever $Q^{m}(\bar{c}-\epsilon) \leq Q^{e}(n, \bar{c})$ where $Q^{m}(\bar{c}-\epsilon)$ is the monopoly output when the marginal cost is $\bar{c}-\epsilon$.

As can easily be seen in the proof, this result requires only that total equilibrium output decreases with a unilateral unit cost increase, which holds universally in Cournot competition with linear costs. Moreover, it can be easily shown that $Q^{m}(\bar{c})<Q^{e}(n, \bar{c})$ and that the monopoly output $Q^{m}(c)$ is decreasing in $c$, which allows to interpret the condition $Q^{m}(\bar{c}-\epsilon) \leq Q^{e}(n, \bar{c})$ as $\epsilon$ being not too large. To get a sense of how restrictive this condition is, consider the special case of a linear inverse demand $p=a-Q$. Then $Q^{m}(\bar{c}-\epsilon) \leq Q^{e}(n, \bar{c})$ if and only if $\epsilon \leq \frac{n-1}{n+1}(a-\bar{c})$. To see why this condition is not very restrictive, note that in this particular setting an innovation is $\operatorname{drastic}^{22}$ if $\epsilon \geq(a-\bar{c})$.

\subsection{Bertrand competition with differentiated products}

Consider an industry consisting of $n$ single-product firms, with constant unit costs $c_{1}, c_{2}, \ldots, c_{n}$. Assume that the goods are imperfect substitutes. Denoting $D_{i}\left(p_{1}, p_{2}, \ldots, p_{n}\right)$ the demand for the good produced by firm $i$, its profit function and reaction correspondence are defined as usual by

$$
\pi_{i}\left(p_{i}, p_{-i}\right)=\left(p_{i}-c_{i}\right) D_{i}\left(p_{i}, p_{-i}\right) \text { and } r_{i}\left(p_{-i}\right)=\arg \max _{p_{i}} \pi_{i}\left(p_{i}, p_{-i}\right) .
$$

\footnotetext{
${ }^{22} \mathrm{~A}$ process innovation is drastic if the cost reduction it leads to is so large that the user of that technology can act as an unconstrained monopolist.
} 
The Bertrand oligopoly is symmetric if the demand functions are symmetric and $c_{1}=\ldots=c_{n} \triangleq c$.

Let $S_{i} \triangleq\left\{\left(p_{1}, p_{2}, \ldots, p_{n}\right) \in R_{+}^{n} \mid D_{i}\left(p_{1}, p_{2}, \ldots, p_{n}\right)>0\right\}$. We assume that for every firm $i$ :

B1 $D_{i}$ is twice continuously differentiable on $S_{i}$.

B2 (i) $\frac{\partial D_{i}}{\partial p_{i}}<0$, (ii) $\frac{\partial D_{i}}{\partial p_{j}}>0$ and (iii) $\sum_{k=1}^{n} \frac{\partial D_{i}(p, p, \ldots, p)}{\partial p_{k}}<0$ over the set $S_{i}$.

B3 $D_{i} \frac{\partial^{2} \log D_{i}}{\partial p_{j} \partial p_{i}}-\frac{\partial \log D_{i}}{\partial p_{j}} \frac{\partial \log D_{i}}{\partial p_{i}}>0$ over the set $S_{i}$, for $j \neq i$.

B4 $\sum_{j=1}^{n} \frac{\partial^{2} D_{i}\left(p_{1}, p_{2}, \ldots, p_{n}\right)}{\partial p_{i} \partial p_{j}}<0$ over the set $S_{i}$.

These conditions are quite general, and are commonly invoked for differentiated-good demand systems. They have the following meanings and economic interpretations. For B2, part (i) is just the ordinary law of demand; part (ii) says that goods $i$ and $j$ are substitutes; and part (iii) is a dominant diagonal condition for the Jacobian of the demand system, which is required to hold only at equal prices (see e.g., Vives, 1999). It says that, along the diagonal, own price effect on demand exceeds the total cross-price effects. B3 says that each demand has (differentiably) strict log-increasing differences in own price and any rival's price. The exact economic interpretation is that the price elasticity of demand strictly increases in any rival's price, which is a very natural assumption (Milgrom and Roberts, 1990). B4 says that the Hessian of the demand system has a dominant diagonal, which is a standard assumption invoked to guarantee uniqueness of Bertrand equilibrium (Milgrom and Roberts, 1990 or Vives, 1999). B2(iii) and B4 hold that own effects of price changes dominate cross effects, for the level and the slope of demand, respectively.

The following result provides sufficient conditions for A1-A5 and A1'-A5' to hold here.

Proposition 7 Under Assumptions B1-B4,

(a) The Bertrand game is of strict strategic complements, and has a unique Bertrand equilibrium.

(b) Firm i's equilibrium price $p_{i}^{*}$ is increasing in $c_{j}$ for any $j$.

(c) Firm $i$ 's equilibrium price $p_{i}^{*}$ and profit $\pi_{i}^{*}$ are differentiable in $c_{i}$ and $c_{j}$ for any $j \neq i$.

(d) Firm $i$ 's equilibrium profit $\pi_{i}^{*}$ is increasing in $c_{j}$ for any $j \neq i$.

In addition, if the game is symmetric, then

(e) the unique Bertrand equilibrium is symmetric.

(f) the equilibrium price increases in $c$.

(g) per-firm equilibrium profit $\pi_{i}^{*}$ is differentiable in $c$, and decreasing in $c$.

We leave to the reader the task of matching the different parts of Proposition 7 to Assumptions A1-A5 and A1'-A5', as this step is quite similar to the Cournot case.

Anderson et. al. (2001) extends the analysis of the effects of taxation to Bertrand competition with differentiated products, and report analogous findings on the cost paradox as in the Cournot case. Since Proposition 7 contains only intuitive results on the effects of cost changes on profits, one concludes that assumptions B2-B4, which are needed for existence and uniqueness of Bertrand equilibrium, also preclude any counter-intuitive effects of exogenous cost increases. This result is more general than those in Anderson et. al. (2001) due to the abscence of concavity assumptions. 


\section{Proposition 8 Under Assumptions B1-B4,}

(i) Condition (8) and, therefore, Conditions (4) and Condition (5) are verified.

(ii) Condition (3) holds whenever $p^{e}(n, \bar{c}) \leq p^{m}(\bar{c}-\epsilon)$ where $p^{m}(\bar{c}-\epsilon)$ is the monopoly price when the marginal cost is $\bar{c}-\epsilon$.

As can be seen from the proof, this result requires only that each firm's equilibrium price increase with a unilateral unit cost increase, which holds in Bertrand oligopoly with linear costs whenever the game is supermodular (i.e, B3 holds). As in the Cournot case, the condition $p^{e}(n, \bar{c}) \leq p^{m}(\bar{c}-\epsilon)$ may also be interpreted as $\epsilon$ being not too large (for a given level of product differentiation) or, alternatively, as product differentiation being sufficiently low (for a given innovation size $\epsilon$ ).

\section{Conclusion}

The issue of patent quality is one of the most serious problems facing the patent system. One negative consequence of the issuance of weak patents on social welfare stems from the legal costs of patent dispute resolution in court. The use of licensing agreements to deter or settle patent litigation allows to avoid those direct costs. It however induces an indirect loss in welfare if the licensing contract that is preferred by the patent holder is socially suboptimal. In the case of an ironclad patent, it is unclear which type of contracts (royalty or fixed fee) is socially preferrable: under royalty licensing the licensees are less efficient than under fixed fee licensing but their number is possibly higher under royalty licensing (see e.g. Kamien, 1992). However, such a tradeoff does not exist for uncertain patents whenever the patent holder prefers to deter litigation (as is very often the case in practice): in this case the patent holder needs to license all potential users of the technology to deter litigation, which implies that the number of licensees will be the same under both licensing schemes. In that case, per-unit royalties are clearly dominated by fixed fees from a social perspective.

This paper provides an analysis of the licensing of uncertain patents in a general framework and derives conditions under which the licensor prefers to use a per-unit royalty contract. In particular, it is shown that will always be the case for (sufficiently) weak patents under a mild condition which is broadly satisfied under Cournot competition with homogeneous products and Bertrand competition with differentiated products. A significant difference with respect to the literature on the licensing of ironclad patents is that we get a clear-cut result: per-unit royalties are preferred by the holder of a weak patent independently of the type of downstream competition, the degree of differentiation between products and whether the patent holder is active or not in the downstream market, while varying any of these three features can overturn the result when ironclad patents are considered.

Our model generates some testable predictions that might be worth investigating. First, our results suggest that per-unit royalty licenses should be more prevalent in industries with a significant proportion of firms holding questionable patents, e.g., industries relying on some new patentable subject matter (biotechnology, software, business methods,...). Second, if the predictions of our model are correct then under the presumption that the EPO is more stringent in checking the 
patentability standards than the USPTO, the use of per-unit royalties should be less prevalent in the EU than in the US.

\section{References}

Allison, J. and M. Lemley, 1998. Empirical evidence on the validity of litigated patents, AIPLA Quarterly Journal 26, 185-277.

Aoki, R. \& J-L. Hu, 1999. Licensing vs. Litigation: The effect of the legal system on incentives to innovate, Journal of Economics \&3 Management Strategy, 8,133-160.

Amir, R.,1996. Cournot oligopoly and the theory of supermodular games, Games and Economic Behavior, 15, 132-148.

Amir, R. and V.E. Lambson, 2000. On the effects of entry in Cournot markets, Review of Economic Studies 67, 235-54.

Anderson, S., A. de Palma and B. Kreider, 2001. Tax incidence in differentiated product oligopoly, Journal of Public Economics, 81, 173-192.

Anand, B., and T. Khanna. The structure of licensing contracts, Journal of Industrial Economics 48, 103-135.

Arrow, K.J., 1962. Economic welfare and the allocation of resources for invention. In: Nelson, R.R. (Ed.), The Rate and Direction of Inventive Activity, Princeton University Press.

Ayres, I. and P. Klemperer, 1999. Limiting patentees' market power without reducing innovation incentives: the perverse benefits of uncertainty and non-injunctive remedies, Michigan Law Review 97, 985-999.

Bhattacharya, S., C. d'Aspremont, S. Guriev, D. Sen, and Y. Tauman, 2012. Cooperating in R\&D: Patenting, licensing and contracting, CORE Discussion Paper 2012/55.

Beggs, A.W., 1992. The licensing of patents under asymmetric information, International Journal of Industrial Organization 10, 171-191.

Bessen, J. and M.J. Meurer, Patent Failure: How Judges, Bureaucrats, and Lawyers Put Innovators at Risk, Princeton University Press 2008.

Bousquet, A., H. Cremer, M. Ivaldi, and M. Wolkowicz, 1998. Risk sharing in licensing, International Journal of Industrial Organization 16, 535-554.

Caballero-Sanz, F., R. Moner-Coloques and J.J. Sempere-Monerris, 2002. Optimal licensing in a spatial model. Annales d'Economie et de Statistique 66, 257-279.

Choi, J.P., 2001. Technology transfer with moral hazard, International Journal of Industrial Organization 19, 249-266.

Choi, J.P., 2010. Patent pools and cross-licensing in the shadow of patent litigation. International Economic Review 51, 441-460.

Encaoua, D. and Y. Lefouili, 2009. Licensing "weak" patents, The Journal of Industrial Economics 57, 492-525. 
Farrell, J. and R.P. Merges, 2004. Incentives to challenge and defend patents: why litigation won't reliably fix patent office errors and why administrative patent review might help, Berkeley Technology Law Journal, Annual Review of Law and Technology 19.

Farrell, J. and C. Shapiro, 2008. How strong are weak patents? American Economic Review 98, 1347-1369.

Février, P and L. Linnemer, 2004, Idiosyncratic shocks in a asymmetric Cournot oligopoly, International Journal of Industrial Organization, 22, 6, 835-848.

Friebel, G., A. K. Koch, D. Prady and P. Seabright, 2006, Objectives and Incentives at the European Patent Office, Report, Institut d'Economie Industrielle, Toulouse.

Gallini, N.T. and B.D. Wright, 1990. Technology transfer under asymmetric information, RAND Journal of Economics, 21, 147-160.

Gans, J., D. Hsu and S. Stern, 2008. The impact of uncertain intellectual property rights on the market for ideas: evidence from patent grant delays, Management Science, 55, 982-997.

Guellec, D. and B. van Pottelsberghe de la Potterie, 2007. The Economics of the European Patent System, Oxford Press.

Kamien, M.I., 1992. Patent licensing. In: Aumann, R.J., Hart, S. (Eds.), Handbook of Game Theory with Economic Applications, Elsevier Science, North Holland, vol. 1, pp. 331-354.

Kamien, M.I., S.S. Oren and Y. Tauman, 1992. Optimal licensing of cost-reducing innovation, Journal of Mathematical Economics 21, 483-508.

Kamien, M.I. and Y. Tauman, 1984. The private value of a patent: a game theoretic analysis, $Z$. Nationalökon 4 (Supplement), 93-118.

Kamien, M.I. and Y. Tauman, 1986. Fees versus royalties and the private value of a patent, Quarterly Journal of Economics 101, 471-491.

Kamien, M.I. and Y. Tauman, 2002. Patent licensing: the inside story, Manchester School 70, 7-15.

Katz, M.L. and C. Shapiro, 1985. On the licensing of innovations, RAND Journal of Economics 16, $504-520$.

Katz, M.L. and C. Shapiro, 1986. How to license intangible property, Quarterly Journal of Economics 101, 567-589.

Kimmel, S., 1992. Effects of cost changes on oligopolists' profits, Journal of Industrial Economics, 40, 4, 441-449.

Langinier, C. and P. Marcoul, 2009. Monetary and mplicit incentives of the patent examiners, Working Paper, University of Alberta.

Lanjouw, J.O., A. Pakes, and J. Putnam, 1996. How to count patents and value intellectual property: Uses of patent renewal and application data, NBER working paper \#5741.

Lei, Z. and B. Wright, 2010. Why weak patents? Rational ignorance or pro- "customer" tilt?, Working Paper, Department of Agricultural and Resource Economics, UC Berkeley.

Lemley, M, 2001, Rational ignorance at the patent office, Northwestern University Law Review 95, 4 Lemley, M., 2012, Fixing the patent office, W.P. 18081, NBER, available at http://nber.org/papers/w18081 
Lemley, M. and C. Shapiro, 2005, Probabilistic patents, Journal of Economic Perspectives 19, 75-98. Macho-Stadler, I. and J.D. Pérez-Castrillo, 1991. Contrats de licence et asymétrie d'information, Annales d'Economie et de Statistique 24, 189-208.

Macho-Stadler, I., X. Martinez-Giralt, X. and J.D. Pérez-Castrillo, 1996. The role of information in licensing contract design, Research Policy 25, 25-41.

Milgrom, P. and J. Roberts, 1990. Rationalizability, learning, and equilibrium in games with strategic complementarities, Econometrica 58(6), 1255-77.

Muto, S., 1993. On licensing policies in Bertrand competition, Games and Economic Behavior 5, $257-267$.

Novshek, W., 1985. On the existence of Cournot equilibrium, Review of Economic Studies L, 85-98. Poddar, S. and U.B. Sinha, 2004. On patent licensing and spatial competition, Economic Record 80, 208-218.

Rockett, K., 1990. The quality of licensed technology, International Journal of Industrial Organization 8, 559-574.

Rostoker, M., 1984. A survey of corporate licensing, IDEA: Journal of Law and Technology 24, 59-92.

Saracho, A.I., 2002. Patent licensing under strategic delegation. Journal of Economics and Management Strategy 11, 225-251.

Seade, J., 1985. Profitable cost increases and the shifting of taxation, The Warwick Economics Research Paper Series.

Sen, D., 2002. Monopoly profit in a Cournot oligopoly, Economics Bulletin 4, 1-6.

Sen, D., 2005a. On the coexistence of different licensing schemes, International Review of Economics and Finance 14, 393-413.

Sen, D., 2005b. Fee versus royalty reconsidered, Games and Economic Behavior 53, 141-147.

Sen D. and Y. Tauman, 2007. General licensing schemes for a cost-reducing innovation, Games and Economic Behavior 59, 163-186.

Sen D. and Y. Tauman, 2012. Licensing of cost-reducing innovation in a Cournot oligopoly, Working Paper, Stony Brook University.

Shapiro, C., 1985. Patent licensing and R\&D rivalry, American Economic Review, Papers and Proceedings 75, 25-30.

Shapiro, C., 2003. Antitrust limits to patent settlements, RAND Journal of Economics 34, 391-411. Stamatopoulos, G., Tauman, Y., 2007. Licensing of a quality-improving innovation, Mathematical Social Sciences, 56, 2008, 410-438.

Topkis, D., 1998. Supermodularity and Complementarity, Princeton University Press.

Taylor, C. and Z. Silberstone, 1973. The Economic Impact of the Patent System, Cambridge Univ. Press, Cambridge.

Vives, X., 1999, Oligopoly pricing: old ideas and new tools, MIT Press, Cambridge, MA. 
Wang, X.H., 1998. Fee versus royalty licensing in a Cournot duopoly model, Economic Letters 60, $55-62$.

Wang, X. H., 2002. Fee versus royalty licensing in a differentiated Cournot duopoly, Journal of Economics and Business, 54, 253-266.

Wang, X.H. and B. Yang, 1999. On licensing under Bertrand competition, Australian Economic Papers 38, 106-119.

Zuniga, P.M. and D. Guellec, 2009, Who licenses out patents and why?, OECD Science, Technology and Industry Working Papers, 2009/5.

\section{$9 \quad$ Appendix}

\section{Proof of Lemma 1}

All firms accepting the license offer is an equilibrium if and only if:

$$
\pi^{e}(n, \bar{c}-\epsilon+r) \geq \theta \pi^{i}(n-1, \bar{c}-\epsilon+r)+(1-\theta) \pi^{e}(n, \bar{c}-\epsilon)
$$

which can be rewritten as:

$$
g(r, \theta) \equiv \pi^{e}(n, \bar{c}-\epsilon+r)-\theta \pi^{i}(n-1, \bar{c}-\epsilon+r)-(1-\theta) \pi^{e}(n, \bar{c}-\epsilon) \geq 0 .
$$

We have $g(0, \theta)=\theta\left[\pi^{e}(n, \bar{c}-\epsilon)-\pi^{i}(n-1, \bar{c}-\epsilon)\right] \geq \theta\left[\pi^{e}(n, \bar{c})-\pi^{i}(n-1, \bar{c}-\epsilon)\right]$ $\geq \theta\left[\pi^{i}(n-1, \bar{c})-\pi^{i}(n-1, \bar{c}-\epsilon)\right]>0$ (by A2 and A5) and $g(\epsilon, \theta)=\pi^{e}(n, \bar{c})-\theta \pi^{i}(n-1, \bar{c})-$ $(1-\theta) \pi^{e}(n, \bar{c}-\epsilon)=(1-\theta)\left(\pi^{e}(n, \bar{c})-\pi^{e}(n, \bar{c}-\epsilon)\right)<0$ (by A2). Combining this with $g$ being continuous (by A1) and strictly decreasing in $r$ (by A3) yields: i/ the existence and uniqueness of a solution in $r$ to the equation $g(r, \theta)=0$ (within the interval $[0, \epsilon[$ ), which we denote by $\tilde{r}(\theta)$; ii/ the equivalence between the inequalities $g(r, \theta) \geq 0$ and $r \leq \tilde{r}(\theta)$.

\section{Proof of Proposition 2}

Since $\tilde{P}_{r}(0)=\tilde{P}_{F}(0)$ then $\tilde{P}_{r}(\theta)>\tilde{P}_{F}(\theta)$ for $\theta$ sufficiently small if:

$$
\left.\frac{d \tilde{P}_{r}(\theta)}{d \theta}\right|_{\theta=0}-\left.\frac{d \tilde{P}_{F}(\theta)}{d \theta}\right|_{\theta=0}>0
$$

which can be rewritten as:

$$
n \tilde{r}^{\prime}(0) q^{e}(n, \bar{c}-\epsilon)>n\left[\pi^{e}(n, \bar{c}-\epsilon)-\pi^{i}(n-1, \bar{c}-\epsilon)\right]
$$

because $\tilde{r}(0)=0$. Moreover differentiating at $\theta=0$ the equation

$$
\pi^{e}(n, \bar{c}-\epsilon+\tilde{r}(\theta))=\theta \pi^{i}(n-1, \bar{c}-\epsilon+\tilde{r}(\theta))+(1-\theta) \pi^{e}(n, \bar{c}-\epsilon),
$$


we get:

$$
\tilde{r}^{\prime}(0)=\frac{\pi^{i}(n-1, \bar{c}-\epsilon)-\pi^{e}(n, \bar{c}-\epsilon)}{\frac{\partial \pi^{e}}{\partial c}(n, \bar{c}-\epsilon)} .
$$

Therefore, (9) is equivalent to:

$$
n \frac{\pi^{i}(n-1, \bar{c}-\epsilon)-\pi^{e}(n, \bar{c}-\epsilon)}{\frac{\partial \pi^{e}}{\partial c}(n, \bar{c}-\epsilon)} q^{e}(n, \bar{c}-\epsilon)>n\left[\pi^{e}(n, \bar{c}-\epsilon)-\pi^{i}(n-1, \bar{c}-\epsilon)\right]
$$

which can be rewritten as:

$$
\frac{\partial \pi^{e}}{\partial c}(n, \bar{c}-\epsilon)>-q^{e}(n, \bar{c}-\epsilon)
$$

because $\pi^{i}(n-1, \bar{c}-\epsilon)-\pi^{e}(n, \bar{c}-\epsilon)<0$.

\section{Proof of Proposition 3}

To prove that $\hat{F}(\theta)=0$ for $\theta$ small enough, it is sufficient to show that the function $h(r, \theta)=$ $r q^{e}(n, \bar{c}-\epsilon+r)+\pi^{e}(n, \bar{c}-\epsilon+r)-\theta \pi^{i}(n-1, \bar{c}-\epsilon+r)-(1-\theta) \pi^{e}(n, \bar{c}-\epsilon)$ is increasing for small values of $r$ and $\theta$ (this follows directly from $\tilde{r}(0)=0$ and $\hat{r}(\theta)$ being continuous in $\theta$ ). We have:

$$
\frac{\partial h}{\partial r}(0, \theta)=q^{e}(n, \bar{c}-\epsilon)+\frac{\partial \pi^{e}}{\partial c}(n, \bar{c}-\epsilon)-\theta \frac{\partial \pi^{i}}{\partial c}(n-1, \bar{c}-\epsilon) .
$$

Let us now assume that $\frac{\partial \pi^{e}}{\partial c}(n, \bar{c}-\epsilon)>-q^{e}(n, \bar{c}-\epsilon)$. We need to distinguish between two cases:

- Case 1: $\frac{\partial \pi^{i}}{\partial c}(n-1, \bar{c}-\epsilon)=0$ : in this $\frac{\partial h}{\partial r}(0, \theta)=\frac{\partial h}{\partial r}(0,0)>0$ for any $\theta \in[0,1]$

- Case 2: $\frac{\partial \pi^{i}}{\partial c}(n-1, \bar{c}-\epsilon) \neq 0$ : in this case $\frac{\partial h}{\partial r}(0, \theta)>0$ for any $\theta \in\left[0, \min \left(1, \frac{q^{e}(n, \bar{c}-\epsilon)+\frac{\partial \pi^{e}}{\partial c}(n, \bar{c}-\epsilon)}{\frac{\partial \pi^{i}}{\partial c}(n-1, \bar{c}-\epsilon)}\right)\right)$.

Therefore, in both cases, $\frac{\partial h}{\partial r}(0, \theta)>0$ for sufficiently small values of $\theta$. Using the continuity of $r \rightarrow \frac{\partial h}{\partial r}(r, \theta)$, we can then state that $\frac{\partial h}{\partial r}(r, \theta)>0$ for sufficiently small values of $r$ and $\theta$, which, as claimed before, is sufficient to complete the proof.

\section{Proof of Proposition 4}

Under the per-unit royalty mechanism, the optimal royalty $\tilde{r}_{I}(\theta)$ for sufficiently weak patents is the solution in $r$ to the following equation:

$$
\pi^{l}(n-1, \bar{c}-\epsilon+r)=\theta \pi^{n}(n-2, \bar{c}-\epsilon+r)+(1-\theta) \pi^{l}(n-1, \bar{c}-\epsilon)
$$

and the patent holder's overall profit is

$$
\tilde{\Pi}_{r}(\theta)=\pi^{p}\left(n-1, \bar{c}-\epsilon+\tilde{r}_{I}(\theta)\right)+(n-1) \tilde{r}_{I}(\theta) q^{l}\left(n-1, \bar{c}-\epsilon+\tilde{r}_{I}(\theta)\right) .
$$

Under the fixed fee mechanism, the optimal fee is given by

$$
\tilde{F}_{I}(\theta)=\theta\left[\pi^{l}(n-1, \bar{c}-\epsilon)-\pi^{n}(n-2, \bar{c}-\epsilon)\right]
$$


and the patent holder's overall profit is then

$$
\tilde{\Pi}_{F}(\theta)=\pi^{p}(n-1, \bar{c}-\epsilon)+(n-1) \theta\left[\pi^{l}(n-1, \bar{c}-\epsilon)-\pi^{n}(n-2, \bar{c}-\epsilon)\right] .
$$

Since $\tilde{\Pi}_{r}(0)=\tilde{\Pi}_{F}(0)$ then $\tilde{\Pi}_{r}(\theta)>\tilde{\Pi}_{F}(\theta)$ for $\theta$ sufficiently small if

$$
\left.\frac{d \tilde{\Pi}_{r}(\theta)}{d \theta}\right|_{\theta=0}>\left.\frac{d \tilde{\Pi}_{F}(\theta)}{d \theta}\right|_{\theta=0}
$$

which can be rewritten as

$$
\tilde{r}_{I}^{\prime}(0)\left[\frac{\partial \pi^{p}}{\partial c}(n-1, \bar{c}-\epsilon)+(n-1) q^{l}(n, \bar{c}-\epsilon)\right]>(n-1)\left[\pi^{l}(n-1, \bar{c}-\epsilon)-\pi^{n}(n-2, \bar{c}-\epsilon)\right] .
$$

because $\tilde{r}_{I}(0)=0$. Moreover, differentiating at $\theta=0$ the equation defining $\tilde{r}_{I}(\theta)$, we get

$$
\tilde{r}_{I}^{\prime}(0) \cdot \frac{\partial \pi^{l}}{\partial c}(n-1, \bar{c}-\epsilon)=\pi^{n}(n-2, \bar{c}-\epsilon)-\pi^{l}(n-1, \bar{c}-\epsilon)
$$

which yields

$$
\tilde{r}_{I}^{\prime}(0)=\frac{\pi^{n}(n-2, \bar{c}-\epsilon)-\pi^{l}(n-1, \bar{c}-\epsilon)}{\frac{\partial \pi^{l}}{\partial c}(n-1, \bar{c}-\epsilon)} .
$$

Hence, inequality (10) is equivalent to $\frac{\pi^{n}(n-2, \bar{c}-\epsilon)-\pi^{l}(n-1, \bar{c}-\epsilon)}{\frac{\partial \pi^{l}}{\partial c}(n-1, \bar{c}-\epsilon)}\left[\frac{\partial \pi^{p}}{\partial c}(n-1, \bar{c}-\epsilon)+(n-1) q^{l}(n, \bar{c}-\epsilon)\right]>(n-1)\left[\pi^{e}(n-1, \bar{c}-\epsilon)-\pi^{i}(n-2, \bar{c}-\epsilon)\right]$ which can be rewritten as

$$
\frac{\partial \pi^{p}}{\partial c}(n-1, \bar{c}-\epsilon)+(n-1) q^{l}(n, \bar{c}-\epsilon)>-(n-1) \frac{\partial \pi^{l}}{\partial c}(n-1, \bar{c}-\epsilon)
$$

or, equivalently, as

$$
\frac{\partial \pi^{p}}{\partial c}(n-1, \bar{c}-\epsilon)+(n-1) \frac{\partial \pi^{l}}{\partial c}(n-1, \bar{c}-\epsilon)>-(n-1) q^{l}(n, \bar{c}-\epsilon) .
$$

\section{Proof of Proposition 5}

(a) This follows from the key slope property that every selection of $r_{i}$ satisfies (see Amir, 1996, and Amir and Lambson, 2000 for details)

$$
-1<\frac{r_{i}\left(Q_{-i}^{\prime}\right)-r_{i}\left(Q_{-i}\right)}{Q_{-i}^{\prime}-Q_{-i}}<0 \text { for all } Q_{-i}^{\prime}>Q_{-i}
$$

(b) We first show that $q_{i}^{*}$ is continuously differentiable in $c_{i}$. Viewed as a correspondence in the parameter $c_{i}, q_{i}^{*}$ is upper hemi-continuous (or u.h.c.), as a direct consequence of the well-known property of u.h.c. of the equilibrium correspondence for games with jointly continuous payoff func- 
tions (e.g., Fudenberg and Tirole, 1990). Since $q_{i}^{*}$ is also single-valued in $c$ (part (b)), $q_{i}^{*}$ must be a continuous function. That $q_{i}^{*}$ is continuously differentiable in $c_{i}$ follows from the Implicit Function Theorem applied to the first order conditions, and the smoothness of $P(\cdot)$. That $\pi_{i}^{*}$ is also continuously differentiable in $c_{i}$ follows from the fact that $q_{i}^{*}$ has that same property for all $i$.

The proof for the parameter $c_{j}, j \neq i$, follows along the same lines.

(c) Throughout part (c), fix $i$ and denote firm $i$ 's output, profit and its rivals' total outputs at equilibrium by $q_{i}^{*}, \pi_{i}^{*}$ and $Q_{-i}^{*}$ respectively when the cost vector is $\left(c_{1}, c_{2}, \ldots, c_{n}\right)$. Denote the same three variables by $\widehat{q}_{i}, \widehat{\pi}_{i}$ and $\widehat{Q}_{-i}$ after firm $i$ 's cost alone changes to $\widehat{c}_{i}>c_{i}$, all other firms' unit costs remaining the same. Adding the $n$ first order conditions at the Cournot equilibrium yields

$$
n P\left(Q^{*}\right)+Q^{*} P^{\prime}\left(Q^{*}\right)=\sum_{k=1}^{n} c_{k} .
$$

Since the LHS of (12) is strictly decreasing in $Q^{*}$, the increase in firm $i$ 's cost from $c_{i}$ to $\widehat{c}_{i}$ increases the RHS of (12), which causes the solution to (12) to decrease. In other words, $\widehat{Q}<Q^{*}$.

We now show that for any firm $j \neq i$, we must have $\widehat{Q}_{-j}<Q_{-j}^{*}$. To this end, first observe that $\widehat{Q}_{-j}+r_{j}\left(\widehat{Q}_{-j}\right)=\widehat{Q}<Q^{*}=Q_{-j}^{*}+r_{j}\left(Q_{-j}^{*}\right)$. Since (11) holds that $Q_{-j}+r_{j}\left(Q_{-j}\right)$ is increasing in $Q_{-j}$, we must have $\widehat{Q}_{-j}<Q_{-j}^{*}$. For firm $j$,

$$
\begin{aligned}
\widehat{\pi}_{j} & =\widehat{q}_{j}\left[P\left(\widehat{q}_{j}+\widehat{Q}_{-j}\right)-c_{j}\right] \\
& \geq q_{j}^{*}\left[P\left(q_{j}^{*}+\widehat{Q}_{-j}\right)-c_{j}\right] \text { by the Cournot property } \\
& >q_{j}^{*}\left[P\left(q_{j}^{*}+Q_{-j}^{*}\right)-c_{j}\right] \text { since } \widehat{Q}_{-j}<Q_{-j}^{*} \\
& =\pi_{j}^{*}
\end{aligned}
$$

We now show that for firm $i$, we must have $\widehat{Q}_{-i}>Q_{-i}^{*}$. To this end, first observe that since for any $j \neq i, r_{j}$ is strictly decreasing (cf. (11)) and $\widehat{Q}_{-j}<Q_{-j}^{*}$, we have $\widehat{q}_{j}=r_{j}\left(\widehat{Q}_{-j}\right)>r_{j}\left(Q_{-j}^{*}\right)=q_{j}^{*}$, for every firm $j \neq i$. Then since $\widehat{Q}_{-i}=\sum_{j \neq i} \widehat{q}_{j}$ and $Q_{-i}^{*}=\sum_{j \neq i} q_{j}^{*}$, we have $\widehat{Q}_{-i}>Q_{-i}^{*}$.

To show that $\pi_{i}^{*}>\widehat{\pi}_{i}$, consider

$$
\begin{aligned}
\pi_{i}^{*} & =q_{i}^{*}\left[P\left(q_{i}^{*}+Q_{-i}^{*}\right)-c_{i}\right] \\
& \geq \widehat{q}_{i}\left[P\left(\widehat{q}_{i}+Q_{-i}^{*}\right)-c_{i}\right] \text { by the Cournot property } \\
& >\widehat{q}_{i}\left[P\left(\widehat{q}_{i}+\widehat{Q}_{-i}\right)-c_{i}\right] \text { since } \widehat{Q}_{-i}>Q_{-i}^{*} . \\
& >\widehat{q}_{i}\left[P\left(\widehat{q}_{i}+\widehat{Q}_{-i}\right)-\widehat{c}_{i}\right] \text { since } \widehat{c}_{i}>c_{i} \\
& =\widehat{\pi}_{i} .
\end{aligned}
$$

For the remaining parts, we consider the case of a symmetric Cournot oligopoly $\left(c_{i}=c\right.$ for all $\left.i\right)$.

(d) Due to the symmetry of the game, asymmetric equilibria, if any, would come in $n$-tuples. Hence, the conclusion follows from part (a) directly. 
(e) Let $q^{*}$ denote per firm equilibrium output. Differentiating the first order condition w.r.t. $c$,

$$
\frac{\partial q^{*}}{\partial c}\left[(n+1) P^{\prime}\left(n q^{*}\right)+n q^{*} P^{\prime}\left(n q^{*}\right)\right]=1 .
$$

Using the first order condition and C3, the term in brackets is strictly negative, so $\frac{\partial q^{*}}{\partial c}<0$.

We now show that per-firm profit decreases in $c$. Denote the equilibrium variables by $q_{i}^{*}, \pi_{i}^{*}$ and $Q_{-i}^{*}$ when the unit cost is $c$, and by $q_{i}^{\prime}, \pi_{i}^{\prime}$ and $Q_{-i}^{\prime}$ the same variables when the unit cost is $c^{\prime}>c$.

Differentiating $\pi_{i}^{*}=q^{*}\left[P\left(n q^{*}\right)-c\right]$ with respect to $c$ yields

$$
\begin{aligned}
\frac{\partial \pi_{i}^{*}}{\partial c} & =\frac{\partial q^{*}}{\partial c}\left[P\left(n q^{*}\right)-c\right]+q^{*}\left[P^{\prime}\left(n q^{*}\right) n \frac{\partial q^{*}}{\partial c}-1\right] \\
& =\frac{\partial q^{*}}{\partial c}(n+1) q^{*} P^{\prime}\left(n q^{*}\right)-q^{*} \text { by }(12) \\
& =-q^{*} \frac{2 P^{\prime}\left(Q^{*}\right)+Q^{*} P^{\prime \prime}\left(Q^{*}\right)}{(n+1) P^{\prime}\left(Q^{*}\right)+Q^{*} P^{\prime \prime}\left(Q^{*}\right)} \text { by }(13) .
\end{aligned}
$$

Clearly, C3 implies that $2 P^{\prime}(Q)+Q P^{\prime \prime}(Q)<0$ for all $Q$, so the numerator in the above fraction is $<0$. It is then easy to see that the denominator is also $<0$. Hence $\frac{\partial \pi_{i}^{*}}{\partial c}<0$.

\section{Proof of Proposition 6}

Let us show that Condition (8) holds (which implies that both Conditions (6) and (7) hold).

Total differentiation w.r.t. $c_{i}$ in $\Pi^{*}=\left(P\left(Q^{*}\right)-c_{i}\right) q_{i}^{*}+\sum_{j \neq i}\left(P\left(Q^{*}\right)-c_{j}\right) q_{j}^{*}$ yields

$$
\frac{\partial \Pi^{*}}{\partial c_{i}}=\left[P^{\prime}\left(Q^{*}\right) \frac{\partial Q^{*}}{\partial c_{i}}-1\right] q_{i}^{*}+\left(P\left(Q^{*}\right)-c_{i}\right) \frac{\partial q_{i}^{*}}{\partial c_{i}}+\sum_{j \neq i}\left[P^{\prime}\left(Q^{*}\right) \frac{\partial Q^{*}}{\partial c_{i}} q_{j}^{*}+\left(P\left(Q^{*}\right)-c_{j}\right) \frac{\partial q_{j}^{*}}{\partial c_{i}}\right]
$$

which can be rewritten as:

$$
\frac{\partial \Pi^{*}}{\partial c_{i}}=-q_{i}^{*}+\sum_{j}\left[P^{\prime}\left(Q^{*}\right) \frac{\partial Q^{*}}{\partial c_{i}} q_{j}^{*}+\left(P\left(Q^{*}\right)-c_{j}\right) \frac{\partial q_{j}^{*}}{\partial c_{i}}\right] .
$$

When $c_{i}=c_{j}=c$, the latter becomes:

$$
\begin{aligned}
\frac{\partial \Pi^{*}}{\partial c_{i}} & =-q_{i}^{*}+\sum_{j}\left[P^{\prime}\left(Q^{*}\right) \frac{\partial Q^{*}}{\partial c_{i}} q_{j}^{*}+\left(P\left(Q^{*}\right)-c\right) \frac{\partial q_{j}^{*}}{\partial c_{i}}\right] \\
& =-q_{i}^{*}+P^{\prime}\left(Q^{*}\right) \frac{\partial Q^{*}}{\partial c_{i}} \sum_{j} q_{j}^{*}+\left(P\left(Q^{*}\right)-c\right) \sum_{j} \frac{\partial q_{j}^{*}}{\partial c_{i}} \\
& =-q_{i}^{*}+P^{\prime}\left(Q^{*}\right) \frac{\partial Q^{*}}{\partial c_{i}} \cdot Q^{*}+\left(P\left(Q^{*}\right)-c\right) \frac{\partial Q^{*}}{\partial c_{i}} \\
& =\underbrace{-q_{i}^{*}}_{\text {direct effect }}+\underbrace{\frac{\partial Q^{*}}{\partial c_{i}}\left[P^{\prime}\left(Q^{*}\right) \cdot Q^{*}+P\left(Q^{*}\right)-c\right]}_{\text {strategic effect }} .
\end{aligned}
$$


Using the Cournot first order condition yields $Q^{*} P^{\prime}\left(Q^{*}\right)+P\left(Q^{*}\right)-c=\frac{n-1}{n} Q^{*} P^{\prime}\left(Q^{*}\right)<0$. From the proof of Proposition 6, $\frac{\partial Q^{*}}{\partial c_{i}}<0$. Hence $\frac{\partial Q^{*}}{\partial c_{i}}\left[P^{\prime}\left(Q^{*}\right) \cdot Q^{*}+\left(P\left(Q^{*}\right)-c\right)\right]>0$, so $\frac{\partial \Pi^{*}}{\partial c_{i}}>-q_{i}^{*}$ in (15).

Let us now show the second part of this proposition. We have

$$
\begin{aligned}
\pi^{e}(n, c)-\pi^{e}\left(n, c^{\prime}\right)-\left(c^{\prime}-c\right) q^{e}\left(n, c^{\prime}\right) & =\left(P\left(n q^{e}(n, c)\right)-c\right) q^{e}(n, c)-\left(P\left(n q^{e}\left(n, c^{\prime}\right)-c\right) q^{e}\left(n, c^{\prime}\right)\right. \\
& =\frac{1}{n}\left[\left(P\left(Q^{e}(n, c)\right)-c\right) Q^{e}(n, c)-\left(P\left(Q^{e}\left(n, c^{\prime}\right)-c\right) Q^{e}\left(n, c^{\prime}\right)\right]\right.
\end{aligned}
$$

It is easy to see from $\mathbf{C} 3$ and $\mathbf{C} 1$ that a monopolist's profit $(P(Q)-c) Q$ is concave. Denoting $Q^{m}(c)$ the monopoly output with marginal cost $c$, it follows that $(P(Q)-c) Q$ is decreasing over the interval $\left[Q^{m}(c), Q^{e}(n, c)\right]$. From Proposition $7(\mathrm{e}), c<c^{\prime}$ implies $Q^{e}\left(n, c^{\prime}\right)<Q^{e}(n, c)$. So the strategic effect $\pi^{e}(n, c)-\pi^{e}\left(n, c^{\prime}\right)-\left(c^{\prime}-c\right) q^{e}\left(n, c^{\prime}\right)$ is negative if $Q^{m}(c) \leq Q^{e}\left(n, c^{\prime}\right)$. Thus, for Condition (3) to hold it is sufficient to have, besides C1-C3, that $Q^{m}(\bar{c}-\epsilon) \leq Q^{e}(n, \bar{c})$.

\section{Proof of Proposition 7}

For firm $i$, charging a price of $c_{i}$ strictly dominates any price below $c_{i}$. Hence, we restrict attention to the price space $\left[c_{i}, \infty\right)$ as the action set for firm $i$. Then $\log \Pi_{i}\left(p_{i}, p_{-i}\right)$ is well defined.

(a) This is well known, see Milgrom and Roberts (1990) or Vives (1999).

(b) The equilibrium price $p_{i}^{*}$ is increasing in $c_{i}$ since (i) the price game is log-supermodular (part (a)), (ii) $\log \Pi_{i}\left(p_{i}, p_{-i}\right)=\log \left(p_{i}-c_{i}\right)+\log D_{i}\left(p_{i}, p_{-i}\right)$ has increasing differences in $\left(p_{i}, c_{i}\right)$, from $\partial^{2} \log \Pi_{i}\left(p_{i}, p_{-i}\right) / \partial p_{i} \partial c_{i}=\left(p_{i}-c_{i}\right)^{-2}>0$, and (iii) the constraint set $\left[c_{i}, \infty\right)$ is ascending in $c_{i}$. So the conclusion follows from [Milgrom and Roberts, 1990, Theorem 7]. That $p_{i}^{*}$ is also increasing in $c_{j}$ for any $j \neq i$ follows from a similar argument since $\partial^{2} \log \Pi_{i}\left(p_{i}, p_{-i}\right) / \partial p_{i} \partial c_{j}=0$.

(c) We first show that every equilibrium price $p_{i}^{*}$ is continuously differentiable in $c_{j}$, for all $i$, $j$. Viewed as a correspondence in the parameter $c_{j}, p_{i}^{*}$ is u.h.c., by the u.h.c. property of the equilibrium correspondence for games with continuous payoff functions (jointly in all actions), see e.g., Fudenberg and Tirole, 1990. Since $p_{i}^{*}$ is also single-valued in $c_{j}$ (from part (i)), $p_{i}^{*}$ is a continuous function. Then the fact that $p_{i}^{*}$ is continuously differentiable in $c_{j}$ follows from the Implicit Function Theorem. Finally, continuous differentiability of $\pi_{i}^{*}$ follows from that of all the $p_{i}^{* \prime} s$.

(d) Differentiating $\pi_{i}^{*}=\left(p_{i}^{*}-c_{i}\right) D_{i}\left(p_{i}^{*}, p_{-i}^{*}\right)$ with respect to $c_{j}$, for $i \neq j$, yields

$$
\frac{\partial \pi_{i}^{*}}{\partial c_{j}}=\frac{\partial p_{i}^{*}}{\partial c_{j}} D_{i}\left(p_{i}^{*}, p_{-i}^{*}\right)+\left(p_{i}^{*}-c_{i}\right) \sum_{k} \frac{\partial D_{i}}{\partial p_{k}} \frac{\partial p_{k}^{*}}{\partial c_{j}} .
$$

Using the first order condition $D_{i}\left(p_{i}^{*}, p_{-i}^{*}\right)+\left(p_{i}^{*}-c_{i}\right) \frac{\partial D_{i}}{\partial p_{i}}=0,(16)$ reduces to

$$
\frac{\partial \pi_{i}^{*}}{\partial c_{j}}=\left(p_{i}^{*}-c_{i}\right) \sum_{k \neq i} \frac{\partial D_{i}}{\partial p_{k}} \frac{\partial p_{k}^{*}}{\partial c_{j}} \geq 0
$$

since $\frac{\partial D_{i}}{\partial p_{k}}>0$ (goods are substitutes) and $\frac{\partial p_{k}^{*}}{\partial c_{j}} \geq 0$ from part (b).

(e) When the Bertrand game is symmetric, the unique Bertrand equilibrium must be symmetric, 
for otherwise equilibria would come in pairs.

(f) The argument is the same as for part (b) since $\partial^{2} \log \Pi_{i}\left(p_{i}, p_{-i}\right) / \partial p_{i} \partial c=\left(p_{i}-c\right)^{-2}>0$.

(g) From an argument similar to the proof of part (c), $p^{*}$ and thus $\pi_{i}^{*}=\left(p^{*}-c\right) D_{i}\left(p^{*}, p^{*}, \ldots, p^{*}\right)$ are differentiable w.r.t. $c$. We derive an expression for $\frac{\partial p^{*}}{\partial c}$. The FOC at a Bertrand equilibrium is

$$
D_{i}\left(p^{*}, \ldots, p^{*}\right)+\left(p^{*}-c\right) \partial D_{i}\left(p^{*}, \ldots, p^{*}\right) / \partial p_{i}=0 .
$$

Using the Implicit Function Theorem and differentiating the FOC with respect to $c$ yields

$$
\left(\frac{\partial D_{i}}{\partial p_{i}}+\sum_{k \neq i} \frac{\partial D_{i}}{\partial p_{k}}\right) \frac{\partial p^{*}}{\partial c}+\left(p_{i}^{*}-c_{i}\right) \frac{\partial p^{*}}{\partial c} \sum_{k} \frac{\partial D_{i}}{\partial p_{k} \partial p_{i}}+\left(\frac{\partial p^{*}}{\partial c}-1\right) \frac{\partial D_{i}}{\partial p_{i}}=0
$$

Hence, using $\mathbf{B 2}$ and $\mathbf{B} 4$,

$$
\frac{\partial p^{*}}{\partial c}=\frac{\partial D_{i} / \partial p_{i}}{2 \frac{\partial D_{i}}{\partial p_{i}}+\sum_{k \neq i} \frac{\partial D_{i}}{\partial p_{k}}+\left(p_{i}^{*}-c_{i}\right) \sum_{k} \frac{\partial D_{i}}{\partial p_{k} \partial p_{i}}}>0
$$

We can differentiate $\pi^{*}=\left(p^{*}-c\right) D_{i}\left(p^{*}, p^{*}, \ldots, p^{*}\right)$ with respect to $c$ to obtain

$$
\begin{aligned}
\frac{\partial \pi^{*}}{\partial c} & =\left(\frac{\partial p^{*}}{\partial c}-1\right) D_{i}\left(p^{*}, \ldots, p^{*}\right)+\left(p^{*}-c\right) \frac{\partial p^{*}}{\partial c} \sum_{k} \frac{\partial D_{i}}{\partial p_{k}} \\
& =D_{i}\left(p^{*}, \ldots, p^{*}\right)\left[-1-\frac{\sum_{k \neq i} \frac{\partial D_{i}}{\partial p_{k}}}{\partial D_{i} / \partial p_{i}} \frac{\partial p^{*}}{\partial c}\right] \text { from }(17) \\
& =D_{i}\left(p^{*}, \ldots, p^{*}\right)\left[-1-\frac{\sum_{k \neq i} \frac{\partial D_{i}}{\partial p_{k}}}{2 \frac{\partial D_{i}}{\partial p_{i}}+\sum_{k \neq i} \frac{\partial D_{i}}{\partial p_{k}}+\left(p_{i}^{*}-c_{i}\right) \sum_{k} \frac{\partial D_{i}}{\partial p_{k} \partial p_{i}}}\right] \text { using (18) } \\
& =D_{i}\left(p^{*}, \ldots, p^{*}\right)\left[-\frac{2 \sum_{k} \frac{\partial D_{i}}{\partial p_{k}}+\left(p_{i}^{*}-c_{i}\right) \sum_{k} \frac{\partial D_{i}}{\partial p_{k} \partial p_{i}}}{2 \frac{\partial D_{i}}{\partial p_{i}}+\sum_{k \neq i} \frac{\partial D_{i}}{\partial p_{k}}+\left(p_{i}^{*}-c_{i}\right) \sum_{k} \frac{\partial D_{i}}{\partial p_{k} \partial p_{i}}}\right]<0 \text { by B2 and B4. }
\end{aligned}
$$

\section{Proof of Proposition 8}

Let us show that Condition (8) holds, which implies that both Conditions (6) and (7) hold. We have $\Pi^{*}=\left(p_{i}^{*}-c_{i}\right) D_{i}^{*}+\sum_{j \neq i}\left(p_{j}^{*}-c_{j}\right) D_{j}^{*}$. Then:

$$
\frac{\partial \Pi^{*}}{\partial c_{i}}=\left(\frac{\partial p_{i}^{*}}{\partial c_{i}}-1\right) D_{i}^{*}+\left(p_{i}^{*}-c_{i}\right) \frac{\partial D_{i}^{*}}{\partial c_{i}}+\sum_{j \neq i}\left[\frac{\partial p_{j}^{*}}{\partial c_{i}} D_{j}^{*}+\left(p_{i}^{*}-c_{i}\right) \frac{\partial D_{j}^{*}}{\partial c_{i}}\right]
$$


which can be rewritten as:

$$
\begin{aligned}
\frac{\partial \Pi^{*}}{\partial c_{i}} & =-D_{i}^{*}+\sum_{j}\left[\frac{\partial p_{j}^{*}}{\partial c_{i}} D_{j}^{*}+\left(p_{j}^{*}-c_{j}\right) \frac{\partial D_{j}^{*}}{\partial c_{i}}\right] \\
& =-D_{i}^{*}+\sum_{j}\left[\frac{\partial p_{j}^{*}}{\partial c_{i}} D_{j}^{*}+\left(p_{j}^{*}-c_{j}\right) \sum_{k} \frac{\partial D_{j}}{\partial p_{k}} \cdot \frac{\partial p_{k}^{*}}{\partial c_{i}}\right] \\
& =-D_{i}^{*}+\sum_{j}\left[\frac{\partial p_{j}^{*}}{\partial c_{i}} D_{j}^{*}+\left(p_{j}^{*}-c_{j}\right) \frac{\partial D_{j}}{\partial p_{j}} \cdot \frac{\partial p_{j}^{*}}{\partial c_{i}}+\left(p_{j}^{*}-c_{j}\right) \sum_{k \neq j} \frac{\partial D_{j}}{\partial p_{k}} \cdot \frac{\partial p_{k}^{*}}{\partial c_{i}}\right] \\
& =-D_{i}^{*}+\sum_{j}[\frac{\partial p_{j}^{*}}{\partial c_{i}} \underbrace{\left(D_{j}^{*}+\left(p_{j}^{*}-c_{j}\right) \frac{\partial D_{j}}{\partial p_{j}}\right)}_{=0}+\left(p_{j}^{*}-c_{j}\right) \sum_{k \neq j} \frac{\partial D_{j}}{\partial p_{k}} \cdot \frac{\partial p_{k}^{*}}{\partial c_{i}}] \\
& =-D_{i}^{*}+\sum_{j}\left[\left(p_{j}^{*}-c_{j}\right) \sum_{k \neq j} \frac{\partial D_{j}}{\partial p_{k}} \cdot \frac{\partial p_{k}^{*}}{\partial c_{i}}\right]
\end{aligned}
$$

We have already shown that $\frac{\partial p_{k}^{*}}{\partial c_{i}}>0$ for any $k, i$ (see the proof for part (b) of Proposition 8). Moreover, we have $\frac{\partial D_{j}}{\partial p_{k}}>0$ for any $j \neq k$ (from B2(ii)). It then follows that $\frac{\partial \Pi^{*}}{\partial c_{i}}>-D_{i}^{*}=-q_{i}^{*}$.

Let us now show the second part of this proposition. Denoting $D_{i}(p, p, \ldots, p) \triangleq D(p)$ and $p^{e}(n, c)$ the (common) equilibrium price when the (common) marginal cost is $c$, we can rewrite the strategic effect of a decrease in the common marginal cost from $c^{\prime}$ to $c$ on individual profits as follows:

$$
\pi^{e}(n, c)-\pi^{e}\left(n, c^{\prime}\right)-\left(c^{\prime}-c\right) q^{e}\left(n, c^{\prime}\right)=\left(p^{e}(n, c)-c\right) D\left(p^{e}(n, c)\right)-\left(p^{e}\left(n, c^{\prime}\right)-c\right) D\left(p^{e}\left(n, c^{\prime}\right) .\right.
$$

Using B2 and B4 we can easily show that the function $(p-c) D(p)$, which can be interpreted as the profit that a multi-product monopolist producing the $n$ varieties and selling them at the same price $p$ derives from each variety, is concave. Denoting $p^{m}(c) \triangleq \arg \max (p-c) D(p)$, it follows that $(p-c) D(p)$ is increasing over $\left[p^{e}(n, c), p^{m}(c)\right]$. We know from part (f) of Proposition 9 that $c<c^{\prime}$ implies $p^{e}(n, c)<p^{e}\left(n, c^{\prime}\right)$. Therefore, we can state that the strategic effect $\pi^{e}(n, c)-\pi^{e}\left(n, c^{\prime}\right)-\left(c^{\prime}-c\right) q^{e}\left(n, c^{\prime}\right)$ is negative if $p^{e}\left(n, c^{\prime}\right) \leq p^{m}(c)$. Thus, for Condition (3) to hold it is sufficient to suppose, beside assumptions B1-B4, that $p^{e}(n, \bar{c}) \leq p^{m}(\bar{c}-\epsilon)$. 